

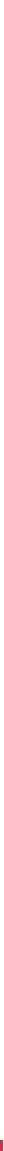

CITACIÓN SUGERIDA

Reconocer, conectar y actuar: porque la ciencia la hacemos todos. Soacha-Godoy, K. y Gómez, N.

(Compiladoras). Bogotá, D.C. 2 y 3 de noviembre de 2016, $53 \mathrm{pp}$, disponible en línea en:

http://hdl.handle.net/20.500.11761/9843

\section{COMPILADORES}

Karen Soacha y Natalia Gómez

LICENCIA

Este documento se publica bajo una licencia Creative Commons de Reconocimiento 4.0 Internacional (CC-BY 4.0)

https://creativecommons.org/licenses/by/4.0/deed.es FOTOGRAFÍAS

Felipe Villegas

REVISIÓN EDITORIAL

Natalia Gómez

DIAGRAMACIÓN Y DISEÑO

César Gutiérrez

DOI 


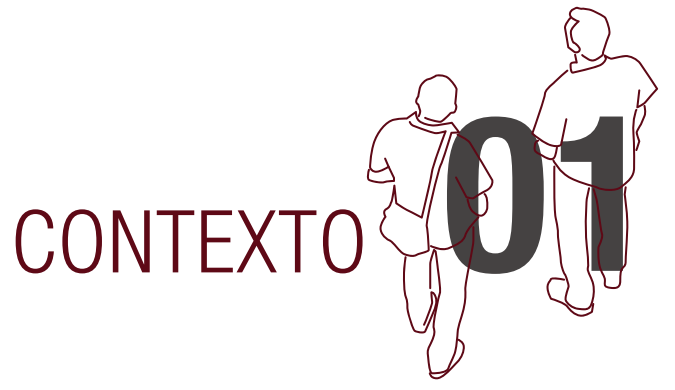

El 2 y 3 de noviembre se realizó en Bogotá el Primer Encuentro de Ciencia Participativa sobre Biodiversidad, un espacio para abrir el diálogo y generar sinergias entre las iniciativas que involucran activamente a la comunidad en la construcción de conocimiento. Este evento, organizado por el Instituto Humboldt y el SiB Colombia, contó con el apoyo de las fundaciones Opepa y Humedales Bogotá, y la participación de cerca de 60 representantes de 27 organizaciones con incidencia nacional e internacional que trabajan proyectos relacionados con el tema central de las jornadas.

El evento contó con tres momentos de trabajo valiosos para el diálogo y la construcción colectiva de propuestas: primero, se realizó una jornada con conferencistas con amplia trayectoria en el tema quienes compartieron su perspectiva académica y pragmática. Los protagonistas de este espacio fueron Antonio Lafuente del Consejo Superior de Investigaciones Científicas y el MediaLab-Prado (España), Marta del Campo del Laboratorio de Ornitología de Cornell (Estados Unidos) y Carlos Rodríguez de la Fundación Tropenbos (Colombia).

Las charlas magistrales abrieron el camino necesario, a partir de la teoría y la práctica, para explorar qué es la ciencia ciudadana, cómo desarrollar procesos de generación de conocimiento de la mano de las comunidades y de qué forma lograr que dialoguen los saberes para complementar y actuar frente a las necesidades de los territorios.

Luego, la jornada permitió que se abriera el espacio para dialogar y construir de manera conjunta un concepto de ciencia participativa a partir de sus conocimientos y experiencias. Finalmente, los asistentes crearon mesas de diálogo y generaron propuestas para la construcción de una ciencia participativa que incida en la toma de decisiones sobre biodiversidad.

Como producto del Encuentro y con el apoyo de los participantes, se generaron memorias gráficas y textuales del evento, un directorio de la comunidad involucrada en estas iniciativas, así como un mapa que permitió identificar más de 70 proyectos en 27 departamentos y la creación de un espacio virtual para dinamizar los lazos estrechados, compartir información y experiencias significativas.

Este documento presenta los resultados del encuentro que, además de la reflexión y el intercambio de experiencias entre diversas organizaciones e iniciativas desarrolladas en el territorio nacional, registra la construcción colectiva de una primera ruta para avanzar en la participación activa de la sociedad civil en la generación de conocimiento científico para la gestión sostenible de la biodiversidad. 


\section{DIANA EUSSE}

Asociación Calidris

Cali, Valle del Cauca

\section{MARTHA OFELIA SUTA FORERO \\ Asociación los Fundadores \\ Fúquene, Cundinamarca}

\section{YECSIKA PACHÓN PATIÑO}

Asociación los Fundadores

Fúquene, Cundinamarca

\section{KATHERINE AREVALO \\ Cabildo Verde \\ Bogotá, D.C.}

ANDRÉS MAURICIO LÓPEZ LÓPEZ Cenicafé

Manizales, Caldas

\section{ROCÍO ESPINOSA \\ Cenicafé \\ Manizales, Caldas}

\section{ÁNGELA BONILLA \\ Colciencias \\ Bogotá, D.C.}

\section{MILDREY MENDOZA}

Colciencias

INGRID MARCELA OBANDO

Colectivo Aves-tamiento en Humedales Bogotá, D.C.

\section{JULIANA CEPEDA VALENCIA \\ Colectivo Sabias y Savias Bogotá, D.C.}

\section{JOSÉ EDILSON ESPITIA BARRERA \\ Congregación de Hermanos de las Escuelas Cristianas \\ Cúcuta, Norte de Santander}

HENRY HERNÁN PAZ SALAS

Corpoamazonía - WWF Colombia - Empresa de Energía de Bogotá Mocoa, Putumayo

\section{PARTICIPANTES

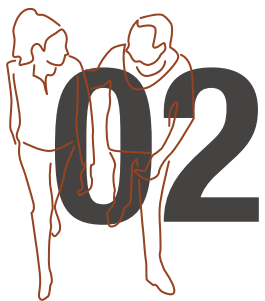

\section{JUAN FELIPE RESTREPO MESA \\ Fundación Ecoprogreso \\ Cartagena, Bolívar \\ CRISTIAN FLÓREZ PAÍ}

Fundación Ecológica Los Colibríes de Altaquer

(FELCA) - Reserva Natural Río Ñambí Pasto, Nariño

\section{EDGARD MEDINA SIERRA \\ Fundación Humedales Bogotá, D.C.}

MAURICIO VALDERRAMA

Fundación Humedales Bogotá, D.C.

SANDRA HERNÁNDEZ BARRERO Fundación Humedales Bogotá, D.C.

DANIEL BERNAL

Fundación Humedales Bogotá Bogotá, D.C.

\section{JORGE ESCOBAR}

Fundación Humedales Bogotá Bogotá, D.C.

SARA E. BENNETT

Fundación Maikuchiga

Leticia, Amazonas

JHON JAIRO VÁSQUEZ GONZÁLEZ

Fundación Maikuchiga Leticia, Amazonas

DIANA LUZ OROZCO TERÁN Fundación Natutama Leticia, Amazonas

SARITA KENDALL

Fundación Natutama Leticia, Amazonas

\section{FEDERICO MOSQUERA-GUERRA}

Fundación Omacha Bogotá, D.C.

\section{LUIS CAMARGO \\ Fundación Opepa Bogotá, D.C.}

ZORAYA BUITRAGO

Fundación Opepa Bogotá, D.C.

JUAN CARLOS CAICEDO

Grupo Ecomunitario Virrey Bogotá, D.C.

MARCELA PARDO PIRACÚN Jardín Botánico de Bogotá Bogotá, D.C.

PATRICIA ALEXANDRA VELÁSQUEZ BERNAL Jardín Botánico de Bogotá Bogotá, D.C.

FERNANDO DUEÑAS VALDERRAMA Museo de Ciencias, Universidad El Bosque Bogotá, D.C.

\section{CAROLINA SANÍN}

Parque Explora

Medellín, Antioquia

FELIPE ÁVILA Seak

Santa Marta, Magdalena

VIVIANA BENAVIDES AYALA Universidad Tecnológica de Pereira Pereira, Risaralda

CARMEN CANDELO

World Wildlife Fund (WWF)

Cali, Valle del Cauca

\section{JAVIER SOACHA} Bogotá, D.C. 


\section{CONFERENCISTAS}

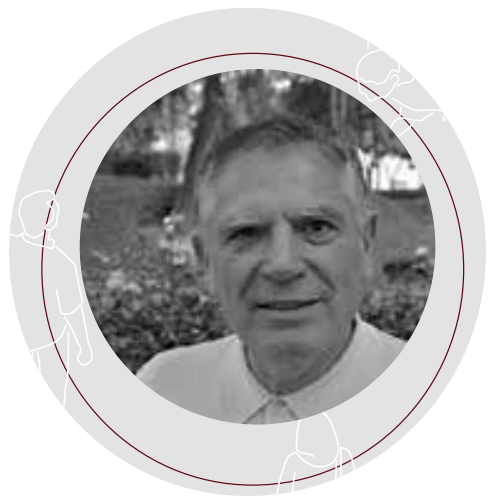

ANTONIO LAFUENTE

Centro de Ciencias Humanas y

Sociales (CSIC)

Madrid, España

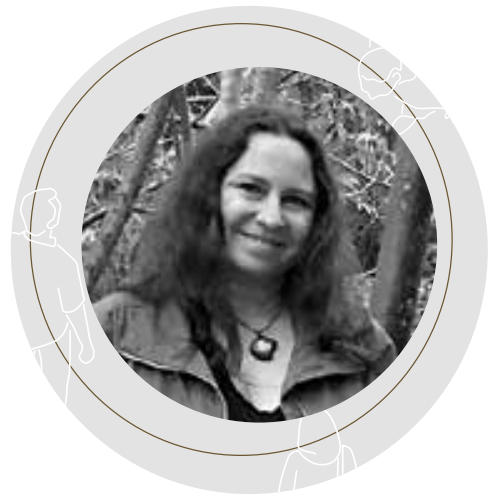

MARTA LUISA DEL CAMPO

Laboratorio de Ornitología de Cornell Ithaca, Estados Unidos

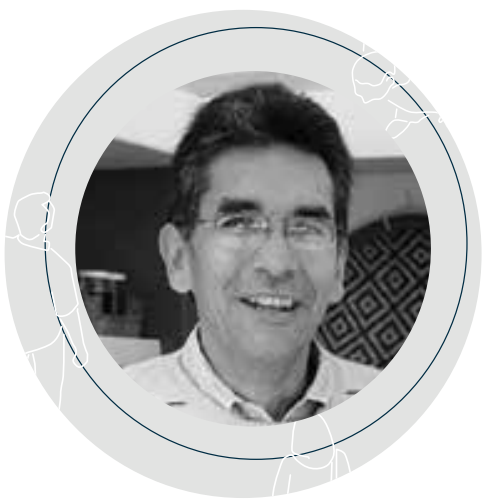

CARLOS RODRÍGUEZ

Fundación Tropenbos

Bogotá, Colombia

\section{INSTITUTO HUMBOLDT}

ALMA HERNÁNDEZ

Programa de Ciencias Básicas de la Biodiversidad

\section{CAROLINA AVELLA}

Proyecto Biodiversidad y Recursos Hídricos en los Andes del Norte

\section{CLAUDIA MARÍA VILLA}

Oficina de Fortalecimiento de Capacidades

\section{CARLOS TAPIA}

Oficina de Asuntos Internacionales, Política y Cooperación

\section{DAIRO ESCOBAR}

Sistema de Información sobre Biodiversidad de Colombia (SiB Colombia)

\section{DIANA RENGIFO}

Oficina de Comunicaciones
FELIPE VILLEGAS

Oficina de Comunicaciones

\section{JAVIER C. BARRIGA}

Programa de Ciencias Básicas de la Biodiversidad

\section{JULIANA MONTOYA}

Programa de Gestión Territorial de la Biodiversidad

KAREN SOACHA

Sistema de Información sobre Biodiversidad de Colombia (SiB Colombia)

\section{LUZ HELENA OVIEDO}

Oficina de Comunicaciones

\section{LAURA CABRERA}

Sistema de Información sobre Biodiversidad de Colombia (SiB Colombia)
MARCELA GALVIS

Proyecto Biodiversidad y Recursos Hídricos en los Andes del Norte

\section{MARÍA CECILIA LONDOÑO}

Programa de Evaluación y Monitoreo del Estado de la Biodiversidad

\section{MARIA CRISTINA RUIZ}

Oficina de Comunicaciones

NATALIA GÓMEZ

Sistema de Información sobre Biodiversidad de Colombia (SiB Colombia)

\section{SANDRA LILIANA MOSQUERA}

Programa de Ciencias Sociales y Saberes de la Biodiversidad

\section{VALERIE DEAN}

Sistema de Información sobre Biodiversidad de Colombia (SiB Colombia) 


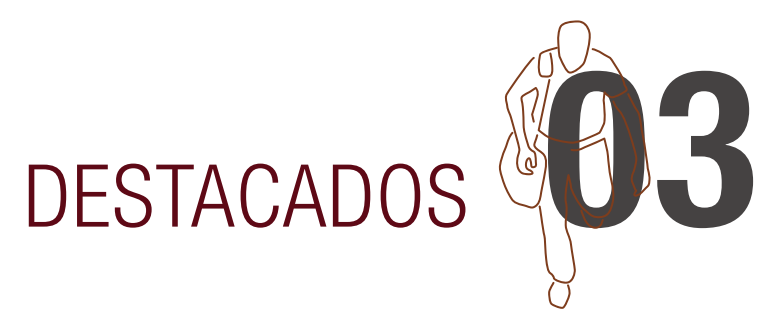

El Primer Encuentro de Ciencia Participativa sobre biodiversidad representó la oportunidad para revisar el panorama nacional y generar la reflexión en torno al tema, no sólo desde su conceptualización, sino también a la luz de la puesta en práctica de los procesos y las realidades propias de los proyectos de investigación que involucran a la sociedad civil.

Este espacio de dos días dejó incontables reflexiones y oportunidades para cada uno de los asistentes, que se espera hayan sensibilizado a los asistentes tanto a nivel personal como organizacional y colectivo.

Los destacados de esta sección son una aproximación para consolidar las principales reflexiones y acuerdos del Encuentro. Sin embargo, el contenido de todo el documento presenta un conocimiento colectivo de gran valor sobre la teoría y la práctica de la ciencia participativa en Colombia que vale la pena leer, y que se encuentra sintetizado a continuación:

- Existen más de 70 proyectos de ciencia participativa y biodiversidad que se encuentran en marcha en Colombia, liderados por 27 organizaciones, principalmente Organizaciones No Gubernamentales (ONG) en 27 departamentos. Su principal reto es la financiación y la generación de visibilidad y alianzas. El fortalecimiento y divulgación de resultados de estas iniciativas es importante, así como evidenciar su aporte a la conservación y la gestión del territorio.

- La variedad de perspectivas relacionadas con el concepto de ciencia participativa es amplia. Existen divergencias especialmente en la denominación: ciencia ciudadana/abierta/participativa o diálogo de saberes. La convergencia se evidenció especialmente a la hora de hablar de su finalidad y cómo se debería construir una ciencia que realmente integre a la sociedad civil. La definición construida fue un primer avance, en el que se reconoce que este concepto es vivo y se transforma en el hacer.

- La ciencia participativa hace posible la construcción de conocimiento a través del encuentro de saberes científicos, empíricos y ancestrales, para la solución de problemas que lleven a mejorar el bienestar de las comunidades y su territorio. Abre los canales para dialogar y resolver los problemas a través de la integración de diferentes perspectivas. Crea puentes entre una amplia diversidad de actores y aumenta la capacidad de colaboración para resolver preocupaciones comunes. Construye una ciencia socialmente válida que incide en la toma de decisiones para la gestión sostenible de la biodiversidad. 
- Las lecciones aprendidas de los participantes -en este primer encuentro de personas que lideran o han coordinado proyectos de ciencia participativa- fueron diversas, se abordaron desde los aspectos clave para iniciar proyectos y/o procesos, la comunidad y su rol elemental, y las preocupaciones u oportunidades.

La mirada holística del problema a investigar, el enfoque multidisciplinar y pluricultural y la integración de los intereses de la comunidad son aspectos clave para desarrollar procesos de ciencia participativa. Entre las preocupaciones se encuentra la falta de financiación especialmente para mantener los procesos en el tiempo, así como identificar cuál es la fórmula para que los proyectos sean procesos, es decir tengan continuidad y no dependan de la presencia de la organización que lo impulsó.

Las oportunidades identificadas giraron especialmente en torno a la integración de la ciencia participativa en el modelo educativo y cómo articular a otros sectores como agricultura y cultura en esta construcción colectiva, una estrategia que permitiría ampliar el impacto de la disciplina.

- La hoja de ruta para lograr un ciencia participativa que incida en la gestión sostenible de la biodiversidad se centró en los siguientes temas: la creación de una rueda de negocios que acerque empresarios y gestores de iniciativas de ciencia participativa para que los encargados de responsabilidad social contemplen procesos relacionados con la biodiversidad y que involucran la comunidad. También se consideró la consolidación de redes de trabajo: en botánica para acabar con la miopía verde, de museos de ciencias e historia natural para llevar la biodiversidad

\begin{tabular}{|r|}
\hline "El Encuentro fue una ventana, una \\
esperanza de poder conectarnos para \\
trabajar en el tema. La posibilidad \\
articuladora que generó, será la \\
puerta para compartir experiencias y \\
escenarios para aprender en colectivo". \\
Luis Camargo. Fundación Opepa.
\end{tabular}
y su conocimiento a los territorios. Finalmente, se dialogó sobre la posibilidad de crear una red de voluntarios para incentivar y fortalecer la participación en estos procesos a nivel nacional.

La mesa de apertura institucional fue una estrategia propuesta para empezar la transformación desde adentro, pues es necesario que las organizaciones se miren, abran sus canales de escucha y empiecen a integrar el diálogo con la sociedad civil como eje para dar respuestas y soluciones a los problemas. La formación de los científicos para innovar en la forma de investigar, la vinculación de las iniciativas y proyectos actuales desde la mirada de la apropiación social del conocimiento y una estrategia de formación para la primera infancia, también estuvieron dentro de las prioridades. Por otra parte, los asistentes consideraron necesario y oportuno planear un encuentro de ciencia participativa para la construcción de la paz y la conservación de la biodiversidad.

La comunidad que participó en el Encuentro creó como canal de comunicación el grupo abierto en Facebook \#CienciaParticipativa Col. El mapeo inicial de los proyectos y el directorio de los participantes consolidado en el Encuentro abre una ventana para visibilizar a futuro estas iniciativas y seguir conectando integrantes.

El reto ahora para los asistentes y las organizaciones que representan, está en hacer realidad estas ideas, así como actuar para hacer posible una comunidad de práctica consistente e interesada en desarrollar proyectos conjuntos que permitan fortalecer el la ciencia participativa en el país. Sin duda, este primer Encuentro fue un paso para avanzar en este propósito colectivo y común de construir la ciencia entre todos. 
CONTEXTO

PARTICIPANTES

DESTACADOS

¿QUÉ ES CIENCIA PARTICIPATIVA?

09

INSUMOS PARA LA CONSTRUCCIÓN

El propósito del Encuentro

El concepto

La práctica

Las experiencias: mirada local

PANORAMA NACIONAL

LECCIONES APRENDIDAS

HOJA DE RUTA

EXPECTATIVAS Y BALANCE DEL ENCUENTRO

EL ENCUENTRO EN IMÁGENES

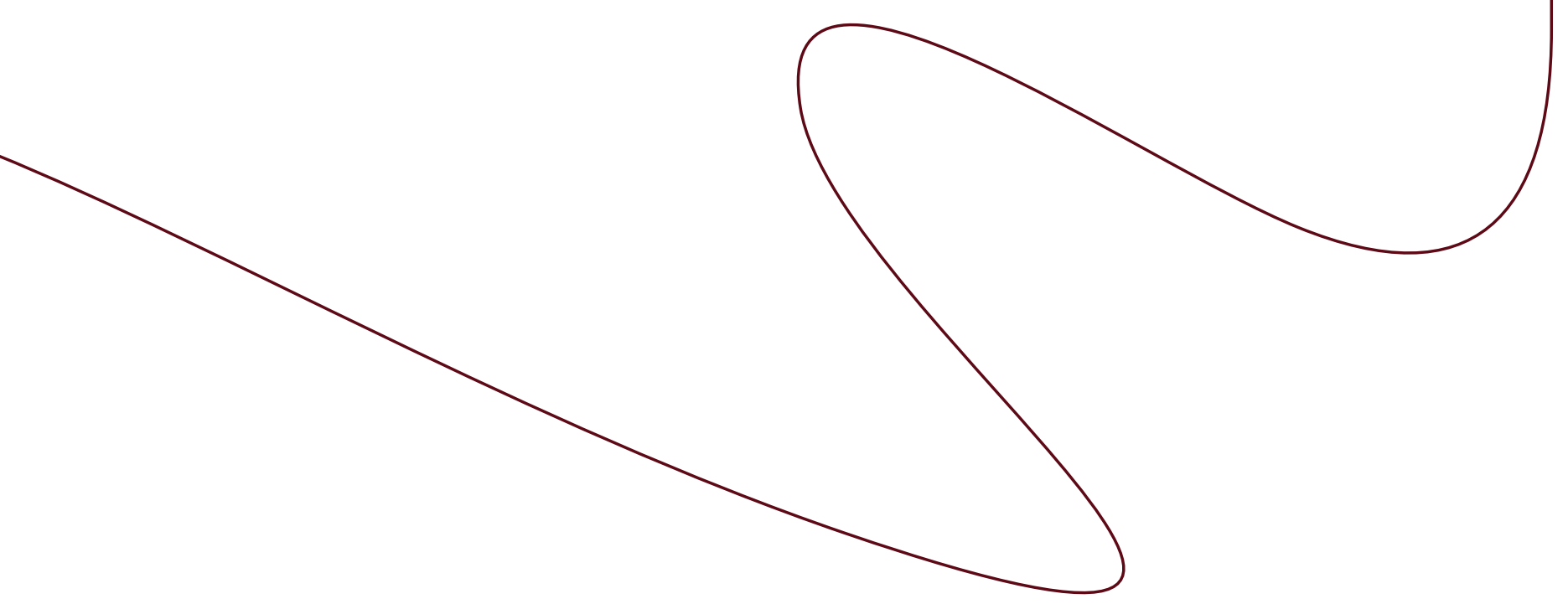




\section{¿QUÉ ES CIENCIA PARTICIPATIVA? 04}

El diálogo y la construcción de una posible definición concertada de la ciencia participativa fue uno de los propósitos previstos para el Encuentro. Para lograr este objetivo, los asistentes trabajaron en grupos para conversar al respecto y proponer una

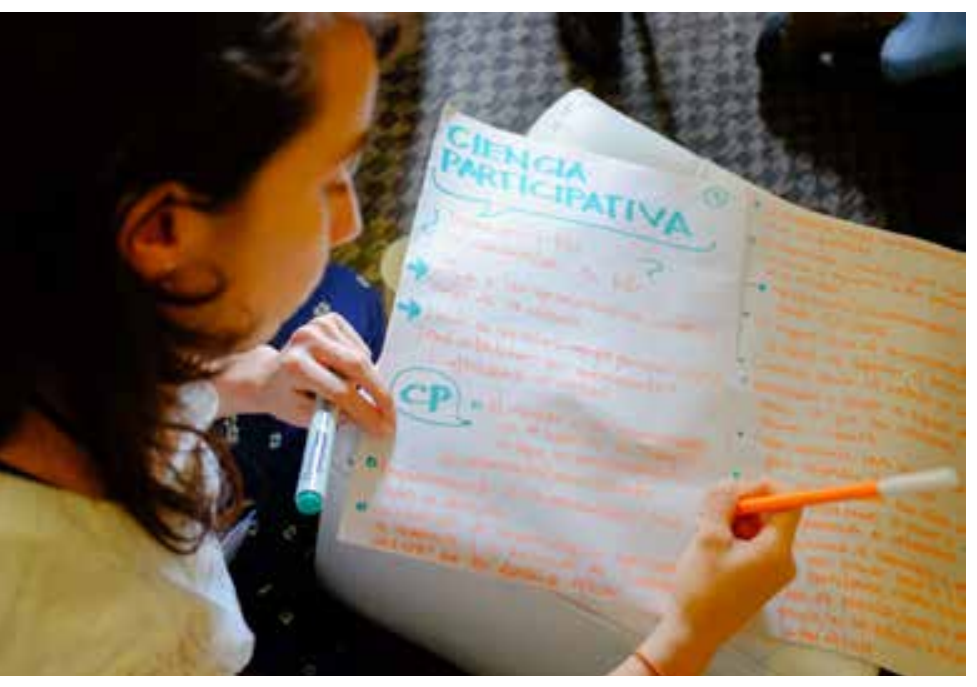
conceptualización como marco de referencia para las acciones futuras para desarrollar después del evento.

El contexto de este ejercicio fue dado por los conferencistas invitados, quienes abordaron el concepto de ciencia ciudadana y ciencia abierta, las experiencias en el diálogo de saberes y las prácticas para el desarrollo de investigaciones participativas. La pregunta que orientó la conversación de los participantes fue: ¿cómo definiría la ciencia participativa y su rol en la conservación de la biodiversidad en Colombia?

Los resultados socializados por cada uno de los ocho grupos permitió encontrar puntos de convergencia y divergencia. Ciencia ciudadana/abierta/participativa o diálogo de saberes, fueron las principales denominaciones alrededor de las cuales no se logró un consenso general. Los participantes se concentraron en definir el cómo y el para qué de la ciencia participativa, en el que se evidenciaron un propósito y expectativas comunes.

Esta construcción colectiva permitió definir a la ciencia participativa como un proceso abierto y dinámico que:

- Se basa en el diálogo de saberes entre diversos intereses y miradas. Suma voces desde la diversidad de conocimiento, cultura y formas de vida.

- Reconoce que todos los involucrados (científicos, comunidad y organizaciones) son conocedores y participan en la construcción de realidad: aportan y aprenden continuamente.

- Promueve procesos de gestión del conocimiento justos, sostenibles y concertados en el territorio.

- Transforma las prácticas de investigación y consolida procesos que contribuyen a la vida digna y la paz. 
- Se orienta a solucionar problemas socioecológicos que buscan el bienestar de las comunidades y los territorios.

- Auna esfuerzos de colaboración, lo se traduce en beneficios como recolectar grandes cantidades de datos e información a través de diversas estrategias, siendo este un medio y no un fin.

- Hace posible el aumento y fortalecimiento de las capacidades de planificación y manejo de las organizaciones.

- Busca contribuir a consolidar modelos gobernanza comunitaria de territorios biodiversos.

- Hace un llamado a la apertura de la ciencia, a través de canales de comunicación que permitan valorar lo experiencial y tejer puentes de colaboración.

La ciencia participativa entonces, como proceso incluyente y articulador (un puente entre expertos y no expertos), tiene un rol clave en la gestión de la diversidad biológica del territorio, pues permite la construcción y fortalecimiento de los vínculos afectivos con la biodiversidad, la toma de conciencia entre los actores y su movilización para conocer y actuar en pro de la conservación y uso sostenible de la biodiversidad.

Trabajar desde la ciencia participativa como modelo para la gestión sostenible de la biodiversidad involucra una metodología basada en la apertura y el diálogo, la construcción colectiva y el reconocimiento de la confianza y el consenso entre los involucrados.

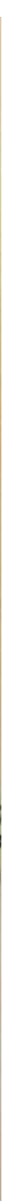




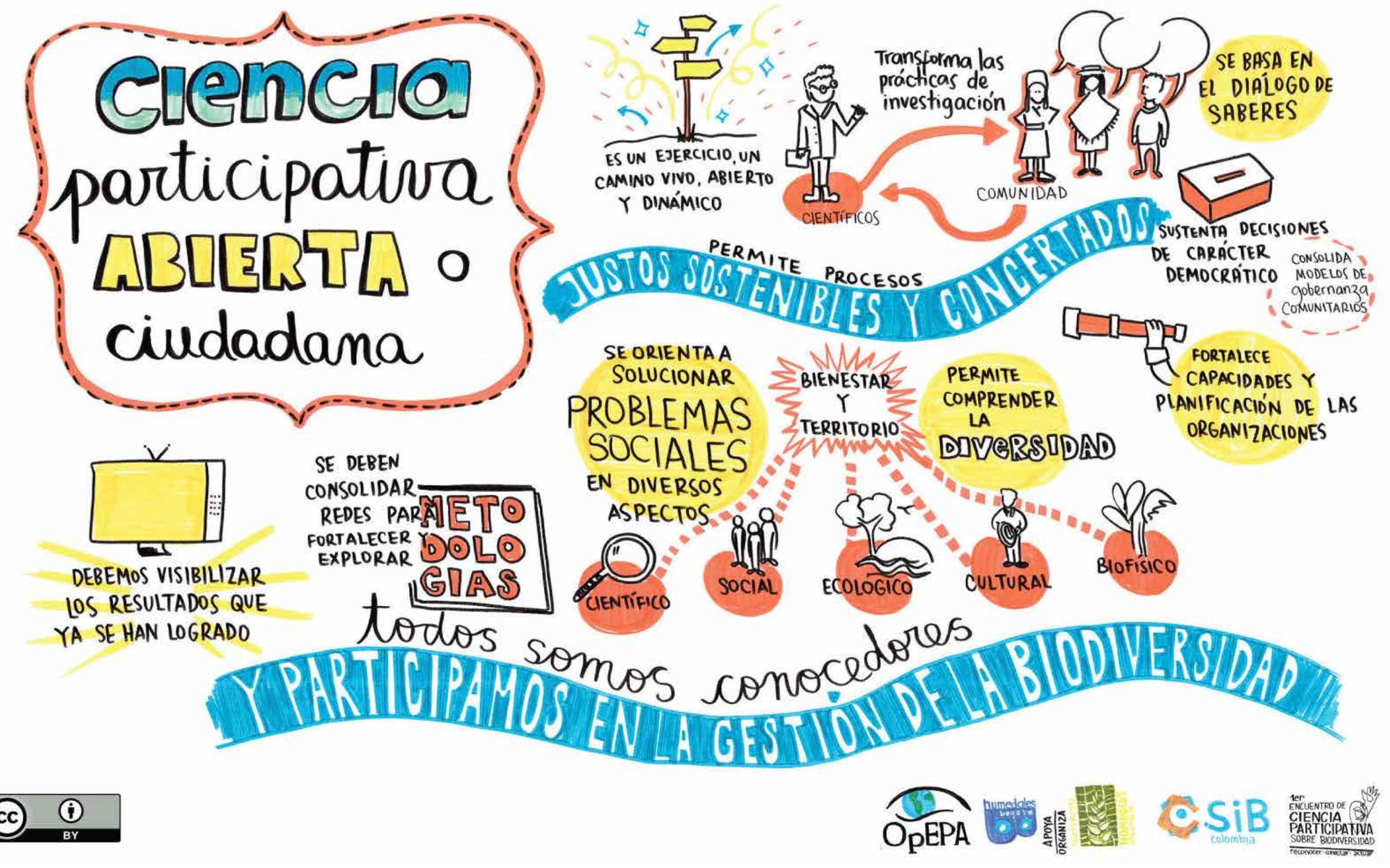




\section{INSUMOS PARA LA CONSTRUCCIÓN

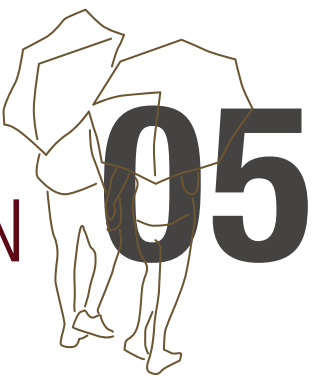

Los conferencistas invitados, con una amplia trayectoria en ciencia y participación pública, compartieron con los asistentes conceptos, experiencias y herramientas de ciencia participativa desde tres enfoques. Por una parte, Antonio Lafuente se devolvió en el tiempo para mostrar cómo desde el origen de la ciencia el público ha sido cómplice y actor indispensable para su existencia. A partir de experiencias, demostró que el concepto de la ciencia abierta/ciudadana/participativa es indispensable para aportar en la solución de los problemas del mundo.

Por otra parte, la metodología de proyectos de ciencia participativa estuvo a cargo de Marta del Campo, quien explicó las bases para adelantarlos de forma exitosa, así como las herramientas que ha desarrollado el Laboratorio de Ornitología de Cornell para facilitar la captura de datos por el público, sin los cuales habría sido imposible responder preguntas de migración o distribución de las aves a escala global.

Finalmente, el diálogo de saberes desde la diversidad cultural para la construcción de conocimiento fue abordado por Carlos Rodríguez. Experiencias que muestran el profundo conocimiento de las comunidades locales sobre su territorio y la biodiversidad que lo habita, dejan clara la necesidad de repensar la aproximación de los científicos a la sociedad. De esta manera, resulta evidente que una de las claves para conocer la biodiversidad está en construir canales abiertos y receptivos para generar un diálogo entre pares.

Algunos de los mensajes principales de sus charlas se resumen a continuación, en la sección Recursos están disponibles las grabaciones completas. 


\section{El propósito del Encuentro}

Charla por Karen Soacha ${ }^{1}$

\section{Reconocer}

- Las personas y organizaciones que han trabajado y siguen avanzando en ciencia participativa en Colombia. Valorar las lecciones aprendidas, construir un concepto común y compartir los retos asociados a la construcción de ciencia para la gestión sostenible de la biodiversidad del país, fueron los objetivos principales del Encuentro.

- Las experiencias globales y las construcciones conceptuales desde la ciencia abierta y ciudadana son insumos indispensables para la creación de un concepto desde Colombia. Existe un creciente interés y documentación a nivel global alrededor de la definición de Citizen Science -más de 5.200 artículos disponibles en Scopus: 3.063 artículos de ciencias sociales y 862 de ecología, biología y conservación-. Sin embargo, la mirada desde Latinoamérica implica además de pensar una denominación en español incluyente, la necesidad de construir un concepto desde la diversidad biológica y desde los saberes y culturas que existen en Colombia.

- Existen diferentes niveles de participación, todos ellos válidos y con objetivos propios. En general, se considera que la ciencia participativa puede tener uno o varios de estos objetivos: conservación, educación e investigación. Los niveles de participación pueden ir desde el contributivo (en el que las personas capturan datos) hasta el co-creado, en el que participan en todas las fases de investigación (desde la formulación de la pregunta hasta el análisis de resultados). En este sentido, existe un gran espectro de oportunidades para construir investigaciones sobre biodiversidad con participación pública.

\section{Conectar}

- Ciencia, política y sociedad: la ciencia participativa posibilita la democratización de la ciencia y el conocimiento, y permite que la sociedad civil -con evidencias tangibles- pueda construir un puente con los tomadores de decisiones.

- Tecnología, comunidad y ciencia: el Instituto Humboldt hace parte de la red global de iNaturalist a través de Naturalista Colombia. Una plataforma digital (web y móvil) que facilita la captura de datos, la creación de guías, la visibilidad de proyectos de ciencia participativa y, especialmente, la conexión entre apasionados por la naturaleza. Expertos y aficionados tienen un sitio de encuentro virtual para compartir sus observaciones, conocimiento e iniciativas sobre la biodiversidad.

Naturalista Colombia está disponible de forma abierta y gratuita para que las iniciativas de ciencia participativa visibilicen sus proyectos, utilicen los datos allí obtenidos para tomar decisiones y conozcan, en general, la biodiversidad nacional a través de las miradas y voces de todos.

\section{Actuar}

- Para definir, construir colaborativamente y compartir el conocimiento, tejer redes y crear nuevas formas de colaboración de la mano de la tecnología, herramientas y buenas prácticas.

La ciencia participativa nos invita a dialogar, unir muchas voces, innovar y cooperar para poder construir en colectivo una ciencia democrática y cercana.

${ }^{1}$ Ingeniera ambiental, especialista en gerencia de recursos naturales y candidata a Magister en Desarrollo Sostenible y Medio Ambiente. Desde 2013 se desempeña como investigadora y Líder de Cooperación del Sistema de Información sobre 

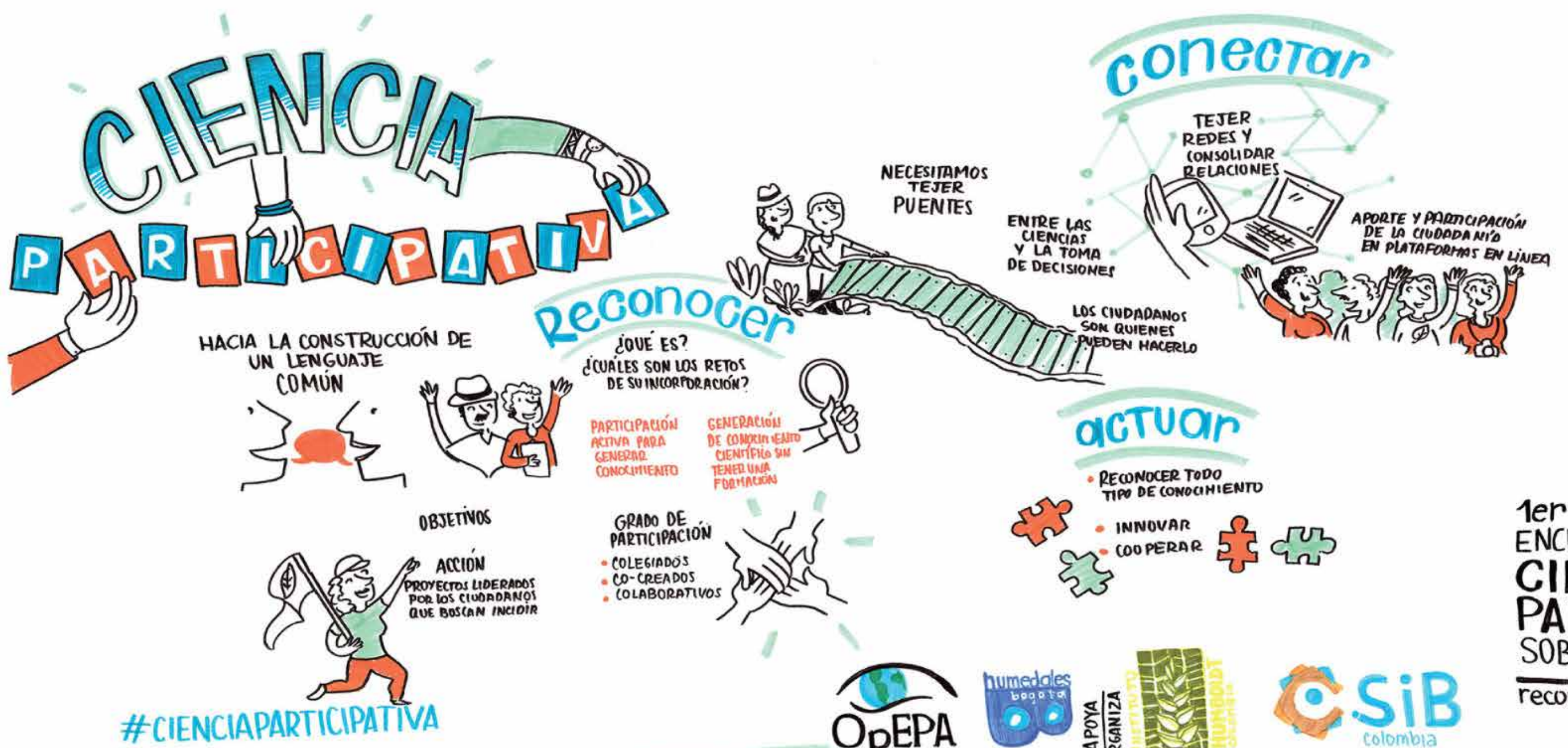
¿COUE ES? ¿CUÁLES SON LOS RETOS

Participación ReTiva Pare

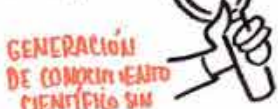

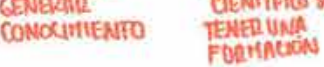

GRADO DE SION - COLEGIADOS - CO-CREADOS

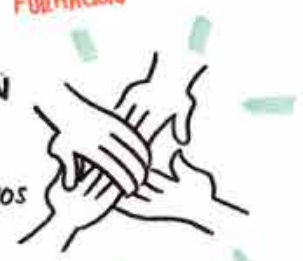

OpEPA

\section{acTUar}

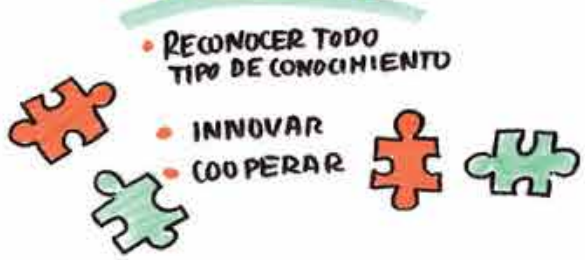

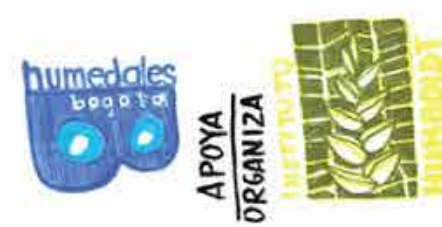

1er

ENCUENTRO DE

CIENCIA PARTICIPATIXA PARTICIPANWA SOBRE BIODIVERSIDAD

(c) (1) 


\section{El concepto}

\section{Ciencia ciudadana y ciencia común}

\section{Charla por Antonio LaFuente ${ }^{2}$}

La ciencia abierta tiene el gran reto de abrir el conocimiento y plantear nuevas formas de hacerlo. Algunos de los elementos clave para la interpretación de la ciencia abierta o ciudadana son el sistema experimental, los expertos en experiencia, la criticidad (Criticality) y el giro experiencial.

El sistema experimental reconoce y abraza la incertidumbre. Desde los expertos en experiencia, se reconocen la diversidad de saberes y especialmente de los hechos, incluso si no hay base conceptual de soporte. La criticidad implica el acercamiento al problema, para poder comprenderlo y lograr desaprender -si fuere necesario-, para luego sí construir conocimiento.

Para el giro experiencial, la ciudadanía desde los movimientos sociales se está configurando como comunidad de aprendizaje que evoluciona de la protesta a la propuesta. Este tránsito en la ciencia también ha mutado para contar con ciudadanos que más allá de reclamar derechos construyen sistemas alternos. Los colectivos dedicados a la construcción de conocimiento han también evolucionado para poner valor a la experiencia o conocimiento experiencial y crear ciencia desde allí.

La ciencia ciudadana o ciencia abierta es entonces la mezcla de estos cuatro conceptos que, en mayor o menor medida, inciden en la sociedad civil para actuar y dar respuesta a sus problemas cotidianos.

Algunas de las experiencias compartidas para ilustrar la necesidad de una ciencia abierta en la resolución de problemas reales, van desde la construcción participativa de un mapa de ruido para un aeropuerto en Estados Unidos que presentaba fallas en su elaboración inicial y por ende afectación a la comunidad circundante, hasta el diagnóstico y reconocimiento de la electrosensibilidad como una enfermedad a partir de una comunidad de afectados en Dinamarca.

La creación de una metodología funcional como la de Alcohólicos Anónimos, también es una práctica de ciencia abierta, que a partir de espacios para compartir experiencias, escuchar y reconocer la vivencia en la voz del otro, permitió avanzar en la forma de tratar las adicciones.

La teoría y las experiencias demuestran que la ciencia es un ejercicio colectivo, en el que más allá de científicos y aficionados, existen personas que buscan resolver problemas comunes, utilizando el conocimiento como el medio para mejorar la calidad de vida.

${ }^{2}$ Investigador científico del Centro de Ciencias Humanas y Sociales (CSIC) en el área de estudios de la ciencia. Ha trabajado en la expansión colonial de la ciencia y la relación de ésta con sus públicos y el conocimiento profano. Desde 2007 dirige el Laboratorio del Procomún en el MediaLab-Prado de Madrid. 


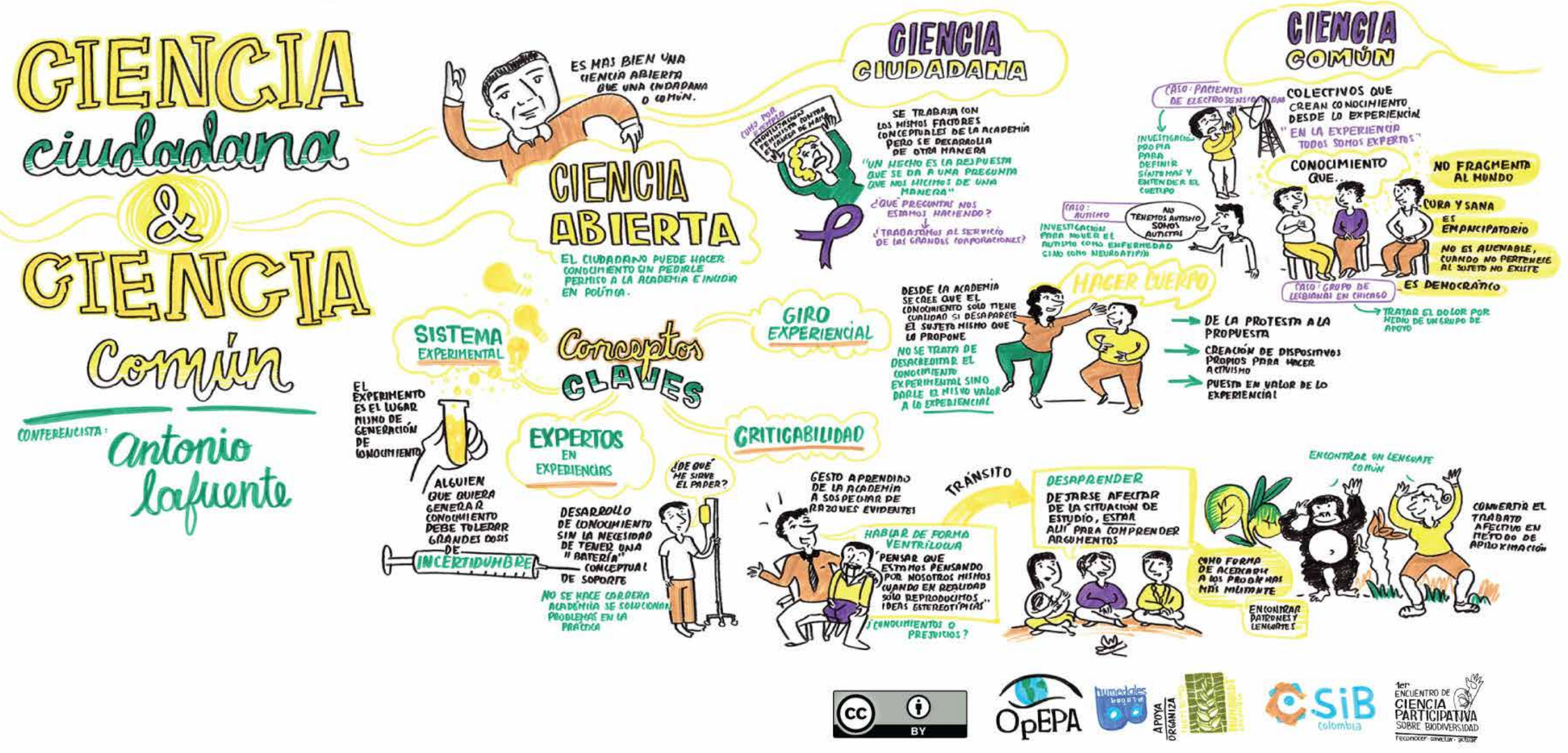




\title{
La práctica
}

\section{Ciencia participativa en la práctica: modelos de inclusión}

\author{
Charla por Marta del Campo ${ }^{3}$
}

El Laboratorio de Ornitología de Cornell ha desarrollado por décadas proyectos de ciencia participativa enfocados en aves, no sólo por su propósito misional, sino porque este énfasis permite educar a la comunidad en este grupo biológico, así como también posibilita abrir espacios para invertir tiempo al aire libre con los participantes, crear conciencia y promover acciones concretas para mejorar la calidad de vida de las aves y su entorno, que es el mismo de la comunidad.

La apuesta del Laboratorio está en la investigación y la ciencia para la educación que lleve a interpretar y conservar la biodiversidad del planeta. Algunas lecciones aprendidas y aspectos metodológicos para compartir como resultado de su amplia experiencia son:

\section{Concepto y finalidad}

- El Laboratorio define la ciencia participativa como el momento en el que muchas personas ayudan voluntariamente a recopilar datos para investigaciones científicas y profesionales. En la ciencia participativa todos son bienvenidos, no importa el perfil (origen, edad, género, etc.) y todas las observaciones son valiosas por lo que pueden proveer. Desde este enfoque se busca la integración e inclusión de la ciudadanía, a través de la exploración de multiplicidad de temas que no podrían investigarse sin el apoyo de la comunidad y que permiten su empoderamiento.

- La ciencia participativa, entonces, es abierta y genera oportunidades educacionales para la comunidad sobre la ciencia y sus procesos; permite también aprender y tomar conciencia de su impacto, así como desarrollar pensamiento crítico y comprensión sobre ella frente a su realización (además de ser una tarea entretenida).

\section{Claves para el desarrollo de proyectos}

- La comunicación y el desarrollo de una relación fuerte con la comunidad involucrada para encontrar valores y metas comunes, es importante. Identificar y definir metas finales desde los intereses y propósitos de la ciencia y de los participantes, así como su impacto en las políticas públicas y la toma de decisiones es fundamental.

- Desarrollar y fomentar nuevas alianzas dentro y fuera de la comunidad de interés también es conveniente a la hora de diseñar y construir un proyecto de ciencia participativa, pues estos procesos fortalecen su ejecución y resultados.

- Co-crear y generar redes para abordar desde programas de trabajo que tengan las organizaciones. La unión para el intercambio de recursos y las relaciones pensadas desde las fortalezas puede ser una apuesta para la construcción de procesos desde este enfoque investigativo. Canadá, por ejemplo, logró la consolidación de la Red Canadiense de Proyectos de Monitoreo Comunitario a través del reconocimiento de organizaciones como el primer paso para luego diseñar el trabajo a realizar.

${ }^{3}$ Bióloga, doctora en entomología de la Universidad de Cornell. Desde 2011, ha trabajado en la integración de las diferentes comunidades latinoamericanas en la ciencia participativa. Actualmente, es la Coordinadora de Alcance Comunitario para Latinoamérica y el Caribe del Laboratorio de Ornitología de Cornell. 
- Garantizar la eficiente administración de los datos, desde la participación y el reconocimiento, hasta la disponibilidad de esa información para las comunidades involucradas.

- La sustentabilidad y la transparencia son primordiales para garantizar la continuidad de un proyecto: generar confianza y reconocimiento a todos los participantes y/o voluntarios asegura futuras posibilidades de trabajo colaborativo.

- Las cualificaciones deben ser certificadas, pues hacen parte de reconocer lo que se hace y quién lo hace.

- Todos los procesos de ciencia participativa son distintos, y por ende, cada situación particular requiere una adaptación y dinamismo que se encuentran estrechamente relacionados con la comunidad con la cual se trabaje.

- La vinculación del arte y la comunicación en los proyectos a través de concursos, talleres, festivales, blogs, y la creación de comunidades de aprendizaje permiten estrechar lazos con los participantes y sus beneficios tangibles.

\section{Herramientas}

- Merlin (aplicación móvil), eBird, NeotropicalBirds, Macaulay Library y Celebrate Urban Birds son algunos de los recursos o iniciativas desarrolladas por el Laboratorio que vale la pena conocer y que se convierten en referentes de ciencia participativa para otras organizaciones. Su propósito, en general, cuenta con un modelo básico que busca la identificación, observación, recolección y disposición abierta de información asociada a las aves. 


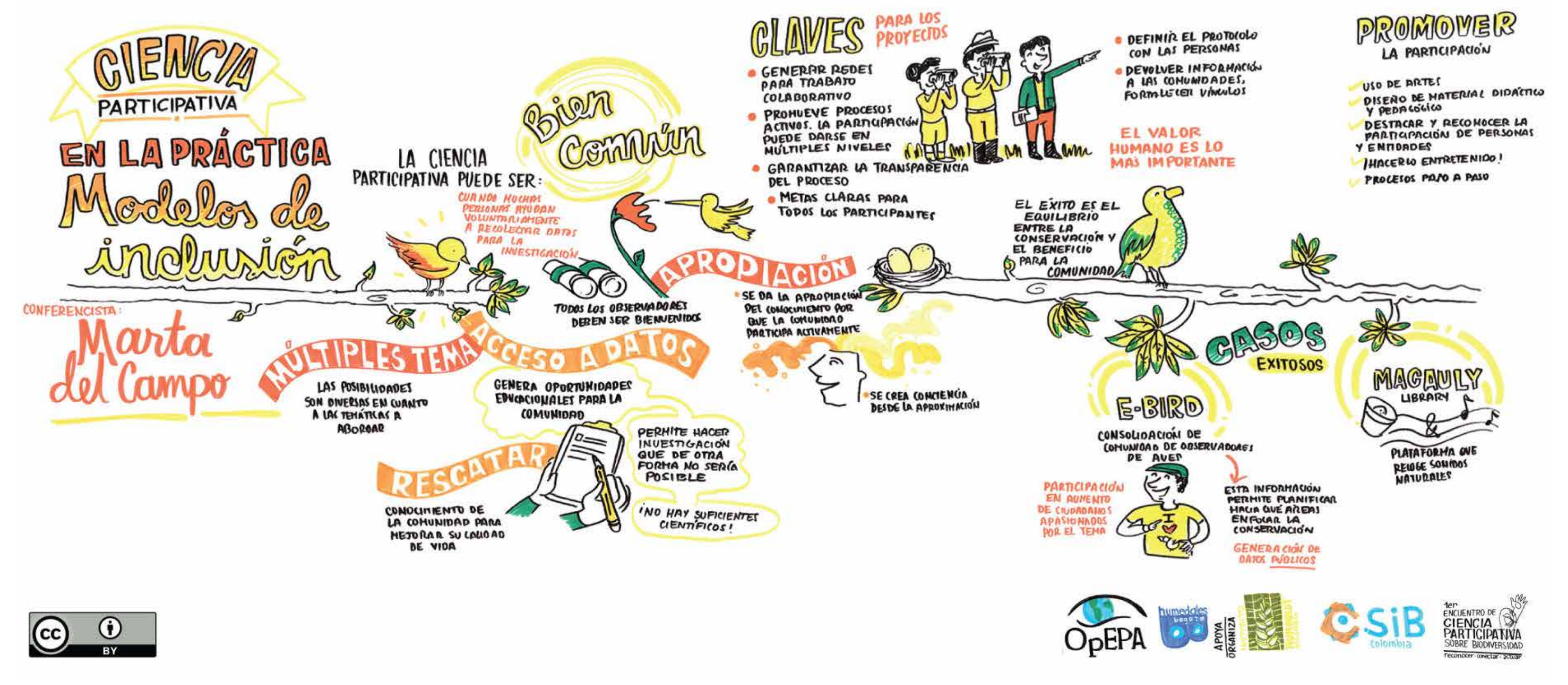




\section{Las experiencias: mirada local}

\section{Dialogar, complementar y actuar}

\section{Charla por Carlos Rodríguez}

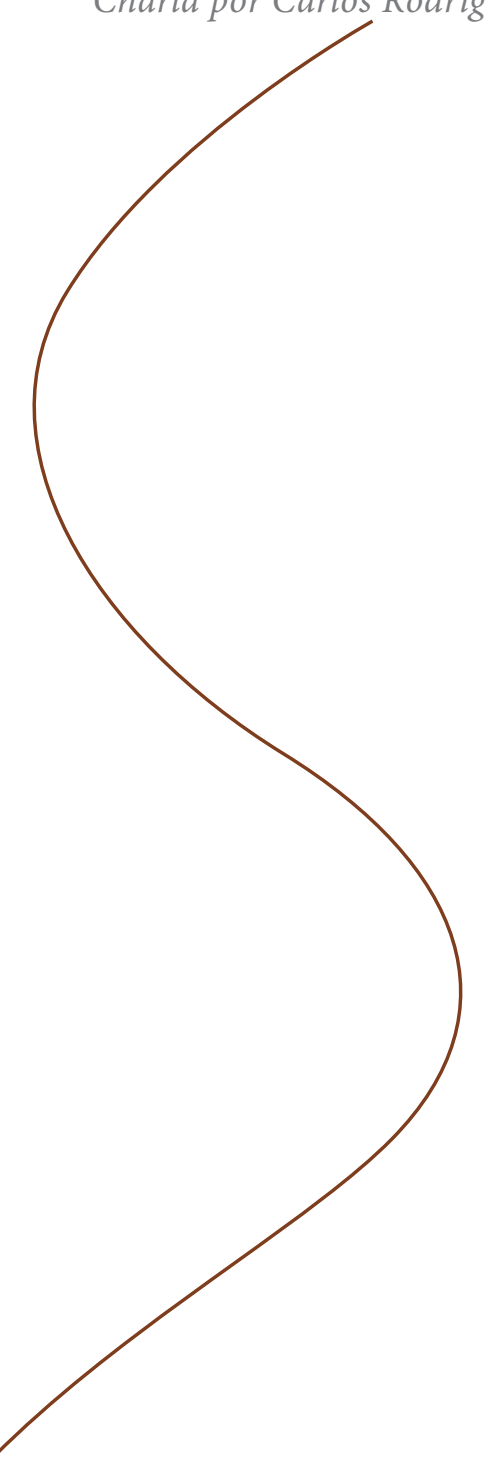

Resultado de un trabajo de décadas con comunidades indígenas en la Amazonía colombiana, Carlos Rodríguez pone en común sus experiencias y la labor desarrollada para la conservación de la biodiversidad a partir del conocimiento ancestral. Algunos de los principales mensajes e invitaciones que hizo a los investigadores se resumen a continuación:

- Gracias a su cosmovisión, las comunidades indígenas tienen un enorme y profundo conocimiento sobre su territorio (geografía, biodiversidad, ecología, agricultura, fenología, etc.). Este se cuenta a través de relatos y en algunos casos dibujos, y pasa de generación en generación. Son múltiples las evidencias de investigaciones que han llegado al territorio desconociendo esta realidad, sin dialogar con las comunidades, lo que resulta en la generación de un conocimiento parcializado y evidentemente menor al que las comunidades ya tienen.

- Hablar del territorio y decir quién lo conoce realmente es una discusión que no sólo incluye a los geógrafos. Los indígenas del Amazonas, por ejemplo, tienen conciencia y conocimiento de su territorio, tanto que cada río, cuenca y quebrada tiene nombre en su lengua madre, denominaciones que son recitadas cada vez que recorren el Amazonas.

- Inventarios de peces generados después de grandes esfuerzos de investigación que resultan claramente incompletos respecto a los que tienen las comunidades, geografía inconclusa, ecología de especies que toman un gran tiempo y esfuerzo para investigar y de la cual los indígenas de la zona llevan décadas comprendiendo, fueron algunas de las experiencias compartidas que hacen un llamado a la apertura y reconocimiento frente a la forma en la cual se investiga.

- Desde el conocimiento local se han logrado desarrollar mapas, investigaciones de biogeografía y ecología de peces. Las comunidades realizan monitoreo de especies en muchos casos. Sin embargo, este conocimiento en algunas ocasiones no tiene gran impacto o no se reconoce desde otras formas de conocer. Uno de los problemas radica en que las investigaciones tienen formas rígidas, formatos y miradas cuantitativas que no concilian con las formas de documentar el conocimiento desde el saber ancestral.

- La Fundación Tropenbos ha logrado trabajar de la mano con las comunidades, generando investigaciones que potencian el conocimiento local. Se han creado becas para que las comunidades indígenas documenten su conocimiento ancestral, buscando siempre beneficiar a la comunidad y la permanencia en el tiempo de esas prácticas y saberes. Para otorgar estas becas ha sido necesario abrir las posibilidades de investigación y pensar de forma diferente los resultados de estos procesos, pues los artículos para este caso no son una opción.

- El saber ancestral es sofisticado y dialógico, su reconocimiento desde la academia y la investigación es totalmente necesario. Esto permitiría aumentar los beneficios colectivos y evitar la pérdida de esfuerzos.

- Para lograr poner a conversar esos dos enfoques de conocimiento (científico y ancestral) es necesario abrir el corazón y la mente, dialogar entre pares, escuchar para complementar conocimientos y actuar en consecuencia.

${ }^{4}$ Biólogo de la Universidad de Los Andes, Máster en planificación del desarrollo regional y urbano del CIDER y Doctor en Ciencias Naturales de la Universidad de Amsterdam. Trabaja desde hace 35 años con comunidades indígenas en temas de conocimiento tradicional y diálogo de saberes.Desde 1998 es Director de la Fundación Tropenbos (Colombia). 


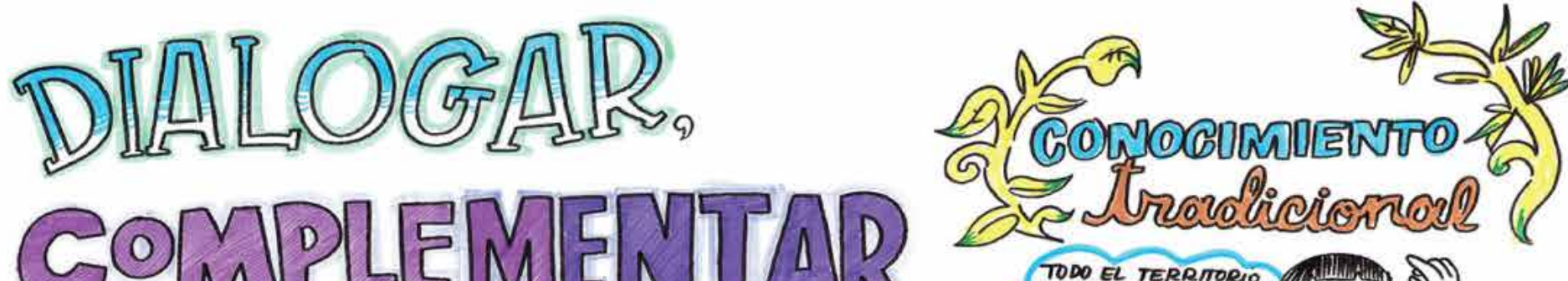
Gomirlemien Ras

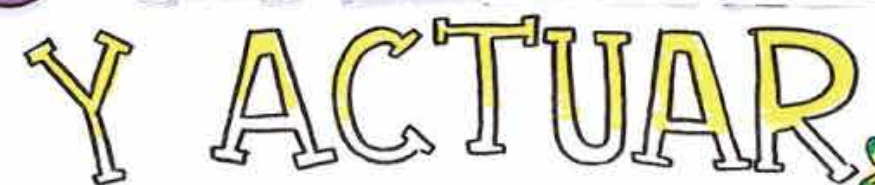

CONFERENGISTA coulos Rodriguez

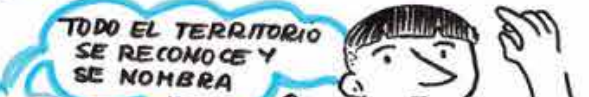

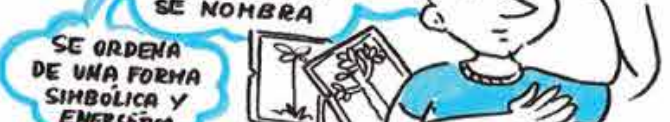

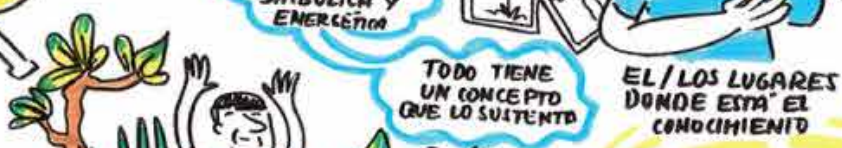

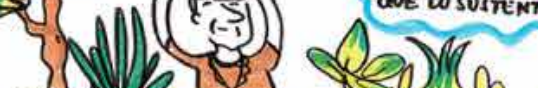

$\mathrm{S}_{0} \mathrm{~d}$ (10iv)

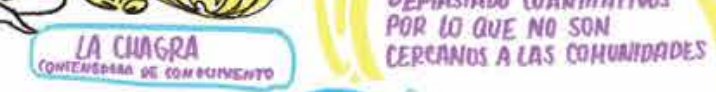

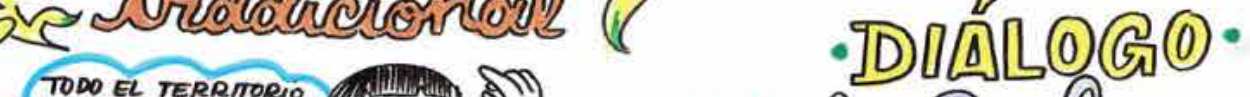

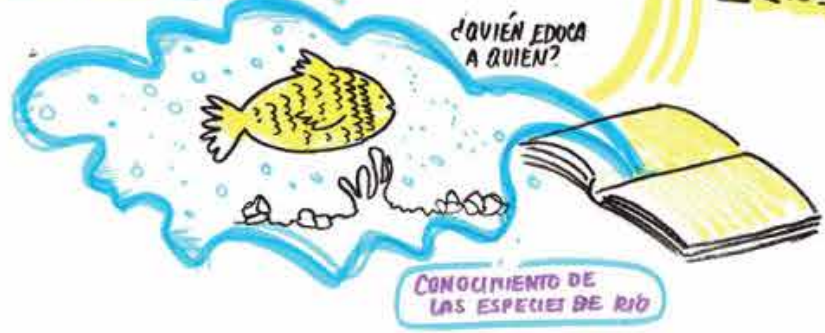

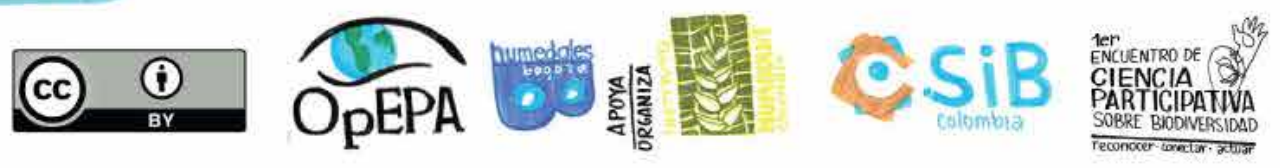

ABRIRNOS DE CORAZON ABPIRNOS OE CYYO UEEOA A

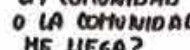

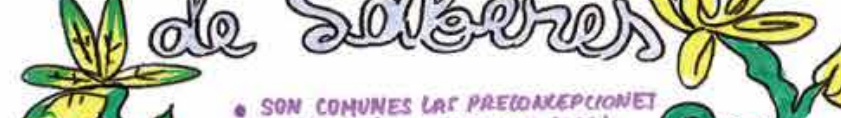

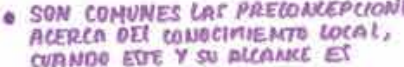

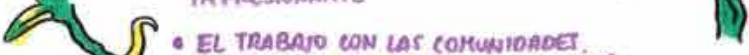

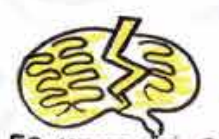

ES NECESARIO REVISAR PRECONCEPTOS Y ENIENDER PARA
ACERCARSE AL CONTETTO

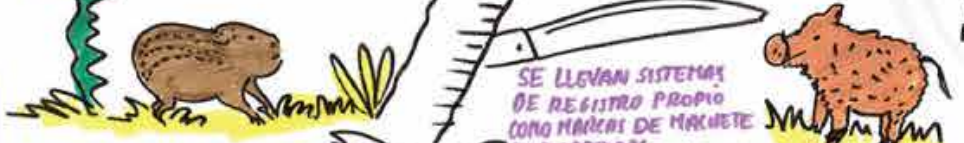

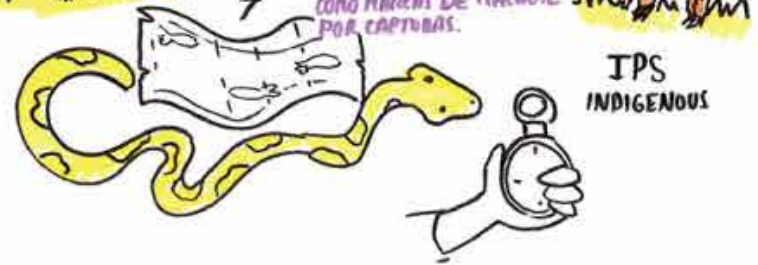




\section{PANORAMA NACIONAL

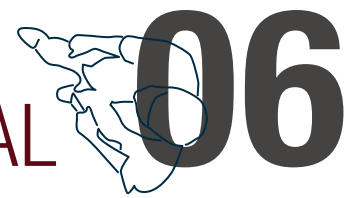

Contar con un mapeo de las iniciativas de ciencia participativa que se adelantan en el país es el primer paso para visibilizarlas y buscar mecanismos conjuntos de fortalecimiento. Colombia ha desarrollado por más de treinta años inventarios y monitoreos participativos de aves: los censos navideños fueron los primeros y ahora se han expandido a censos acuáticos y de aves migratorias. También existen experiencias de participación que han involucrado a las comunidades no sólo en la recolección de datos sino en otras fases de la investigación.

Sin embargo, hoy no se cuenta con un espacio de consulta que facilite conocer los proyectos, participar en ellos, identificar sinergias, compartir lecciones y resolver retos conjuntos. Sumado a la baja documentación disponible y de fácil acceso (publicación de avances y resultados, datos, evaluación de impacto) sobre proyectos de ciencia participativa en el país, que hace difícil contar con un panorama nacional claro y definido.

El Encuentro permitió dar el primer paso, conectar a las personas que gestionan estos procesos y mapear 74 proyectos que se encuentran en desarrollo en 27 departamentos, y que comparten propósitos, oportunidades y retos. Un número importante de estos proyectos involucran la realización de inventarios y monitoreo participativo.

Los retos a superar priorizados por los participantes fueron la financiación, especialmente para lograr mantener los proyectos en el tiempo; seguido de la visibilidad y las alianzas.

De las 27 organizaciones asistentes, 15 fueron ONG. Aunque es una muestra de las iniciativas en ciencia participativa relacionada con temas de biodiversidad, durante la planeación del Encuentro fue posible identificar que son principalmente este tipo de organizaciones las que adelantan proyectos con este enfoque.

La experiencia de las personas vinculadas a estas organizaciones representan un gran potencial de intercambio de experiencias y generación de sinergias en el país. La mayoría de los asistentes han participado por más de seis años en procesos de ciencia participativa y manifestaron su interés en seguir conectados y trabajar conjuntamente para ampliar el impacto de estas actividades en el país.

Crear un espacio de encuentro para esta comunidad de gestores de procesos de ciencia participativa permitió iniciar la construcción de un lenguaje común. Para muchos participantes fue un descubrimiento saber que hacían ciencia participativa desde hace años y que existen muchos otros como ellos en el país. Reconocerse fue una oportunidad y el primer paso para avanzar en los objetivos comunes.

Esta primera ventana de un panorama nacional es un avance para resolver algunas preguntas: ¿hacemos ciencia participativa?, ¿quiénes?, ¿dónde?, ¿cuáles son las lecciones aprendidas? Asimismo, es un camino que trae nuevos interrogantes: ¿cuáles son los impactos de estos procesos de ciencia participativa para la ciencia, las personas y los sistemas socioecológicos?, ¿qué facilita y qué dificulta desarrollarlos en Colombia?, ¿cómo planearlos, desarrollarlos y evaluarlos? y ¿cómo mantenerlos en el tiempo? Para responderlas es indispensable sumar más voces y nuevas miradas, especialmente las de aquellos que hacen realidad la ciencia participativa: la sociedad civil. 


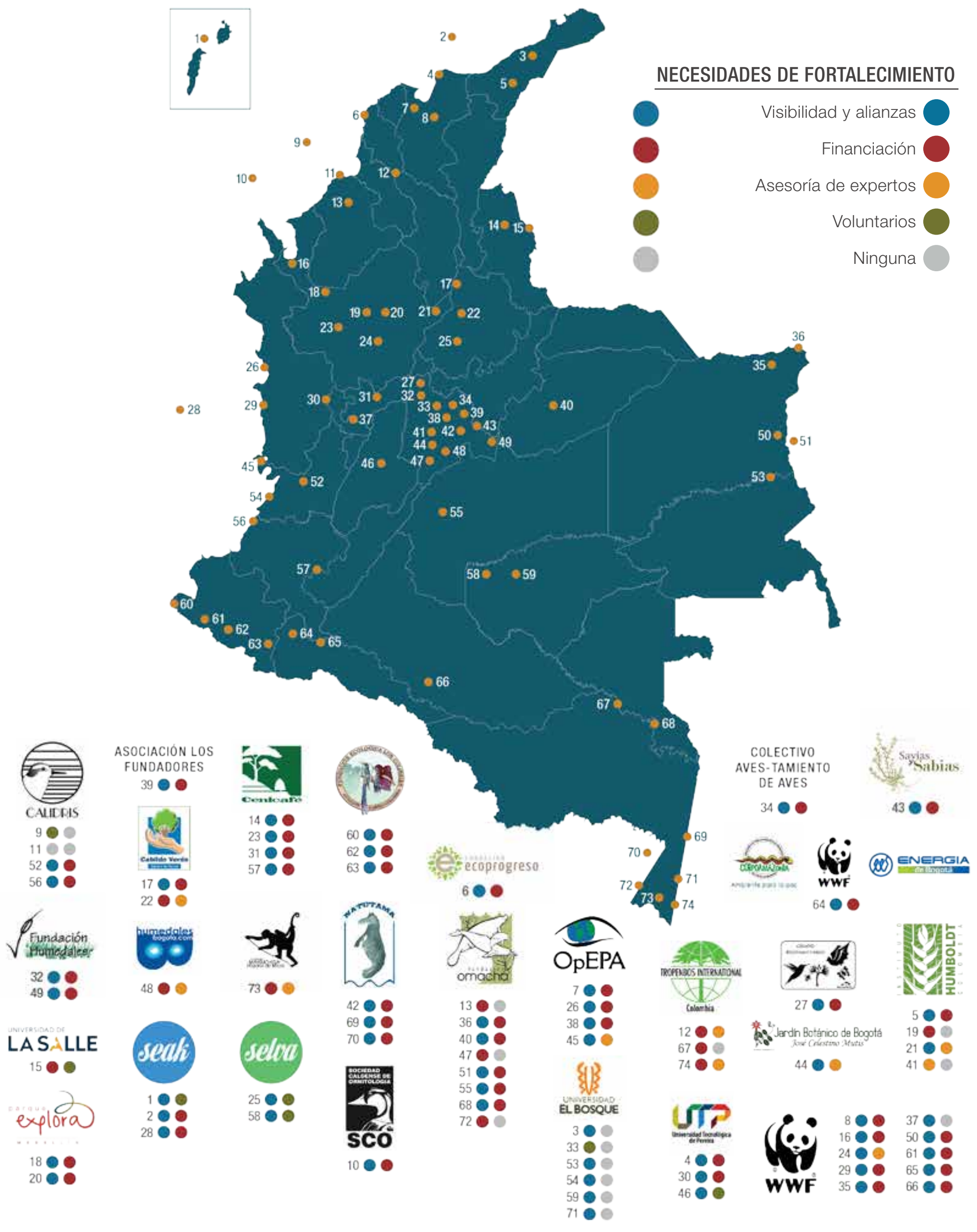


El mapeo de proyectos de ciencia participativa fue un ejercicio colectivo en el que los participantes ubicaron geográficamente cada uno de los proyectos que están adelantando y priorizaron dos necesidades de fortalecimiento para cada uno. Las opciones estaban entre financiación, voluntarios, asesoría de expertos y visibilidad y alianzas.

En total se lograron mapear 74 proyectos, de los cuales es posible obtener unas primeras cifras:

- 20 organizaciones tienen entre 1 a 3 proyectos de ciencia participativa.

- 4 organizaciones tienen entre 4 a 6 proyectos: Asociación Calidris, Fundación Opepa, Instituto Humboldt y Universidad El Bosque.

- Fundación Omacha con 8 y WWF con 10 son las organizaciones con el mayor número de proyectos.

- Los departamentos con el mayor número de proyectos son Cundinamarca (13), Amazonas (8) y Antioquia (8). En los demás varía de $1 a 4$.

- A nivel de región: se concentran 29 en la región Andina, 14 en la Amazonía, 13 en el Caribe, 11 en el Pacífico y 6 en Orinoquía.

- 5 proyectos (8\% del total de mapeados) están en áreas marinas.

- Existen proyectos en 27 departamentos.

\section{Priorización de aspectos a fortalecer en los proyectos}

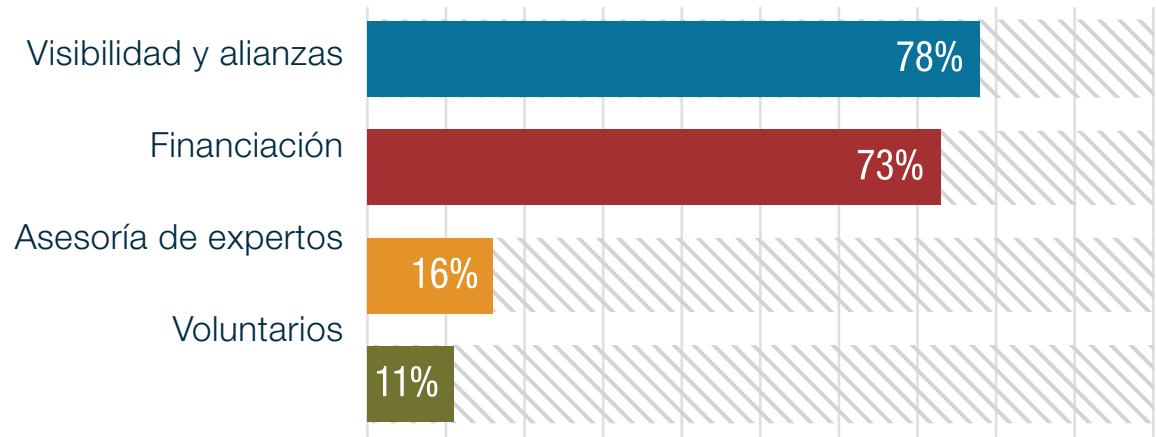

Visibilidad-alianzas y financiación fueron los principales aspectos priorizados por cerca del $75 \%$ de los proyectos. Doce iniciativas se encuentran en busca de voluntarios y ocho requieren asesoría de expertos. 


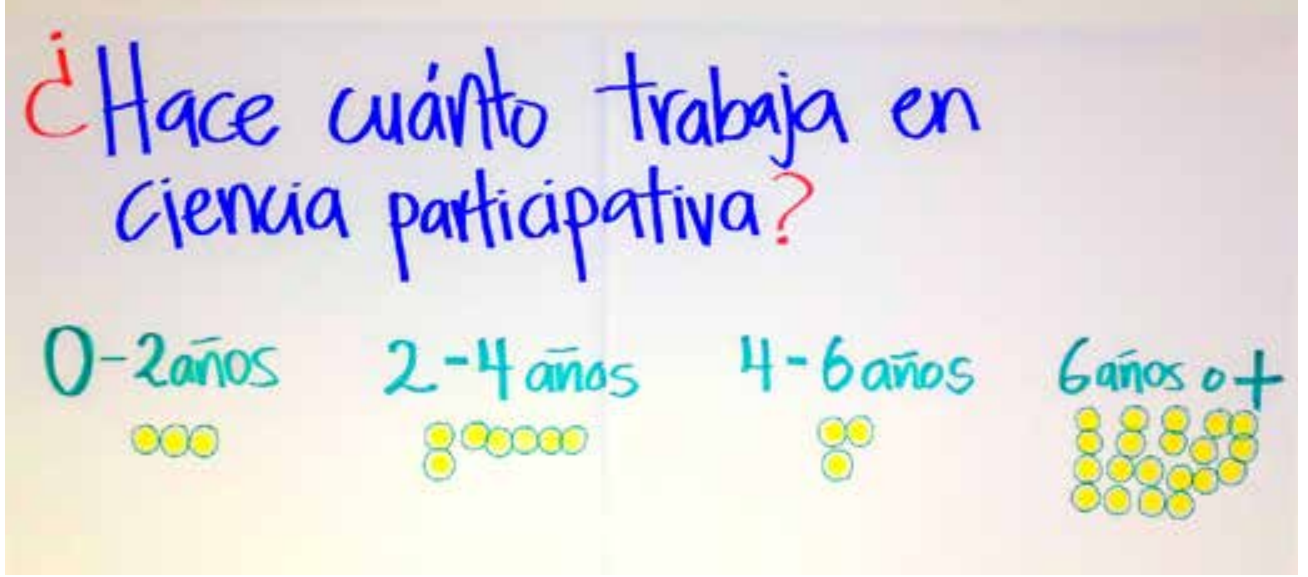

Cerca del $67 \%$ de los asistentes llevan trabajando más de seis años en ciencia participativa. Esto representa una oportunidad para compartir lecciones aprendidas, potenciar esa experiencia para crear sinergias, replicar proyectos y comprender la construcción de la ciencia desde la realidad colombiana.

\section{Tipo de organizaciones participantes}
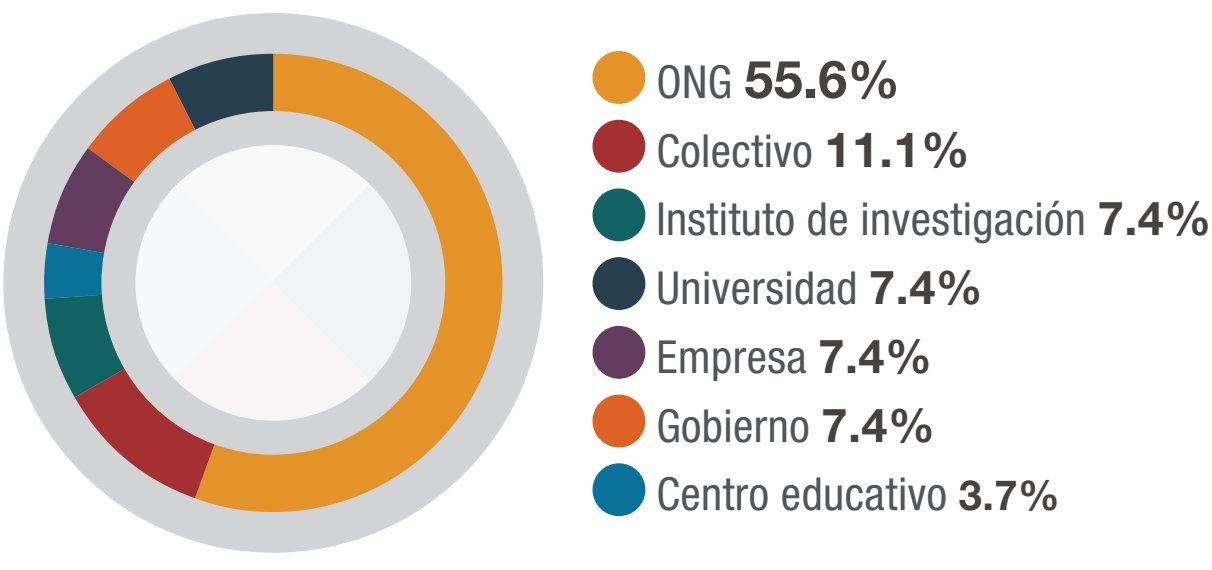

De las 27 organizaciones participantes, 15 fueron ONG. La invitación al Encuentro fue realizada de forma directa y respondió a una exploración preliminar de experiencias en ciencia participativa. Adicionalmente se realizó una consulta con diversas organizaciones sobre la experiencia en este tipo de proyectos para vincularlos a la sesión.

Las ONG que trabajan con conservación de la biodiversidad regularmente actúan a nivel local y por lo tanto consideran clave el trabajo con la comunidad. La generación de conocimiento y el tejido de lazos de colaboración en el territorio, son probablemente las razones que soportan el por qué son los que más gestionan este tipo de iniciativas. 


\section{LECCIONES APRENDIDAS

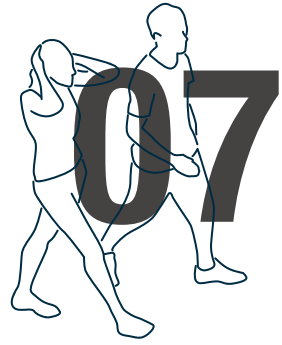

Compartir las experiencias, escuchar las expectativas, frustraciones y ponerse en los zapatos del otro, fue el ejercicio al que se invitó en el grupo de apoyo de ciencia participativa. Gracias a la metodología de "la pecera", los participantes abrieron sus corazones para contar qué les preocupa, qué los motiva, cómo han avanzado y superado los retos para hacer realidad estos procesos.

Para quienes hasta ahora inician o proyectan emprender este camino, escuchar a personas con más de seis años de experiencia fue una gran oportunidad. La diversidad de perspectivas reinó en este grupo: desde la sociología con una crítica muy fuerte a los procesos científicos y la legitimidad de las diversas formas de conocer, hasta quienes ven en este camino una posibilidad para transformar la educación ambiental.

Arrullos y currulaos como una manera distinta de documentar el conocimiento de la comunidad de la mano con nuevas generaciones que invitan a la innovación, fueron el cierre perfecto para ver desde una perspectiva diferente los retos de la ciencia participativa.

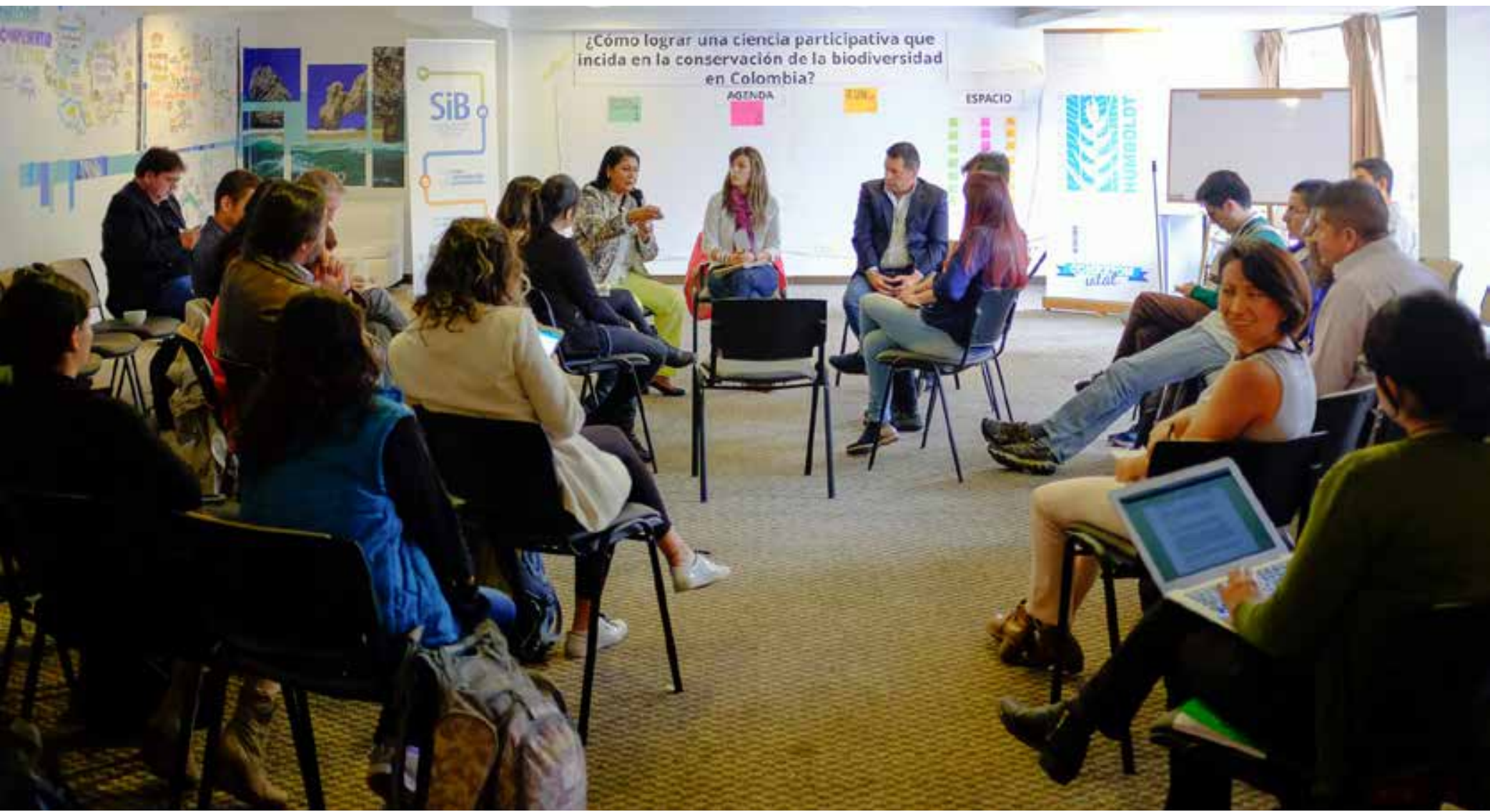


Experiencia, expectativas, nuevos caminos y ante todo un sueño para construir juntos con los pies puestos en la tierra se combinaron en este grupo, que dio lugar a las siguientes reflexiones:

\section{Las claves para iniciar}

- Es necesario entender de forma holística el problema a investigar y ser humildes con las otras formas de conocer.

- Trabajar con sensibilidad para entender los territorios.

- Comprender a la biodiversidad como un estilo de vida para conocerla e involucrarnos en su conservación.

- Es necesario tener claras las metas y los propósitos de las iniciativas de ciencia participativa en biodiversidad, así como las posibilidades para integrarlas en proyectos complementarios que aumenten su impacto y prioricen la importancia de la biodiversidad.

- Los procesos de ciencia participativa necesitan un enfoque multidisciplinario y pluricultural.

- Es indispensable involucrar a las personas, identificar y vincular sus intereses.

- Es importante que la ciencia dé respuesta a los temas claves que la sociedad pregunta.

\section{La comunidad}

- Es necesario pensar en cuál es la estrategia para que las comunidades se sumen y tengan claro lo que realizará la organización.

- La disposición de los actores y la validación de su voluntad es necesario a la hora de desarrollar proyectos participativos.

- El rol de la mujer es vital en estos procesos.

- La participación de los niños es clave.

- En lo local se necesita voluntad política para que estos proyectos avancen.

- En algunos procesos los campesinos han pasado a ser promotores ambientales. La retribución económica ha tenido resultados positivos, perciben que "les pagan por aprender".

- Es necesario visibilizar a todos los actores en los resultados. En algunas experiencias que han desarrollado planes de investigación participativo local, los cazadores han pasado a ser co-investigadores.

\section{Las sinergias}

- Existen muchas redes alrededor de temas relacionados con biodiversidad, pero es importante generar esfuerzos articulados, que seguramente redundarán en resultados fortalecidos. 


\section{Las preocupaciones}

- Existe un angustia frente al laberinto institucional en los temas ambientales en Colombia que diluye las investigaciones y su impacto.

- Es más fácil conseguir financiación para iniciar los proyectos de ciencia participativa que para mantenerlos.

- Genera mucha frustración que los proyectos no continúen desde lo local y cuando la organización para su intervención, el proyecto no continúa.

- "No sabemos cómo mantener el compromiso de las personas, cómo mantener el monitoreo participativo en el tiempo. No siempre hay un líder en la comunidad".

- "Los biólogos no tenemos formación social, me parte el alma la falta de enfoque social. Interrumpimos un flujo normal de la naturaleza y de las comunidades y en muchas ocasiones no dejamos nada para el territorio".

- En los temas urbanos la biodiversidad no es prioridad, las personas hablan de violencia, género y otros. Es necesario convencer a las comunidades urbanas de la biodiversidad, dado que es un tema invisible y la desconexión con este es altísima.

- "Soy sociólogo y no creo en la ciencia. Se encajonan en disciplinas y formatos que hacen que la sociedad no resuelva los problemas. El conocimiento social para el cambio tiene la dificultad de afrontar la trayectoria que traemos de cajitas, es muy difícil".

- "Somos como tribus separadas: Ciencia y Sociedad".

- El desarrollo de actividades de ciencia participativa es difícil con los profesores de colegio. En muchos casos no hay interés. En los colegios públicos resulta aún más complejo. Parece existir un bajo interés y la transferencia a los docentes es difícil.

- En algunos casos los colegios tienen baja disposición de trabajo al aire libre.

- Los escenarios de participación pueden resultar interesantes para procesos de política que en algunos casos afectan positiva o negativamente las actividades.

- En ocasiones se ve que la ciencia "seria" la hacen algunos pocos, pero la ciencia participativa es "bonita".

- Es necesario mantener y en algunos casos desarrollar el espíritu crítico en los procesos. En algunas comunidades es complejo invitar a la crítica como una vía para identificar y solucionar problemas, dado que no se considera que "existan problemas". Es necesario pensar en la lúdica para incentivar esto.

- "No sé si lo que hago es ciencia, activismo o qué".

\section{Las oportunidades}

- Fortalecer el turismo científico es una ventana de oportunidad.

- Invitar a participar a otros sectores y entidades como los Ministerios de Agricultura, Educación, Cultura ya que la biodiversidad es parte del patrimonio y de la cultura del país. 
- Orientar esfuerzos a los niños. Existe un potencial importante desde el programa de vacaciones científicas del Jardín Botánico que está orientado a niños de 5 a 12 años.

- "Tenemos un modelo de educación conductista en el que lo esencial queda de lado". En ese sentido, es necesario replantear el modelo educativo colombiano, derribar las barreras imaginarias y tener modelos integradores para una educación más pertinente y auténtica.

- Pensar en cambios educativos estructurales es fundamental para poder hacer ciencia participativa desde nuestros entornos.

- Integrar los proyectos de ciencia participativa en la educación: en una experiencia de caracterización de aves, integraron las actividades del proyecto con las competencias que evaluaba la escuela. La propuesta es conectar las salidas, realizar aprendizaje activo enlazado y/o vinculado con las clases de ciencias o sociales.

- Ante el reto de hacer que las comunidades prioricen la biodiversidad, es posible desarrollar una estrategia orientadora que genere conciencia y permita avanzar en el nivel de comprensión.

\section{Los interrogantes}

- ¿Ciencia participativa es diferente al diálogo de saberes?

- ¿De qué manera se reconoce la trayectoria de los diferentes actores?

- ¿Cómo construir puentes entre la ciencia y la sociedad civil?

- ¿Cómo se motiva el monitoreo comunitario?

- ¿Cómo se genera continuidad en los procesos?

- ¿Cómo no usamos a las personas?

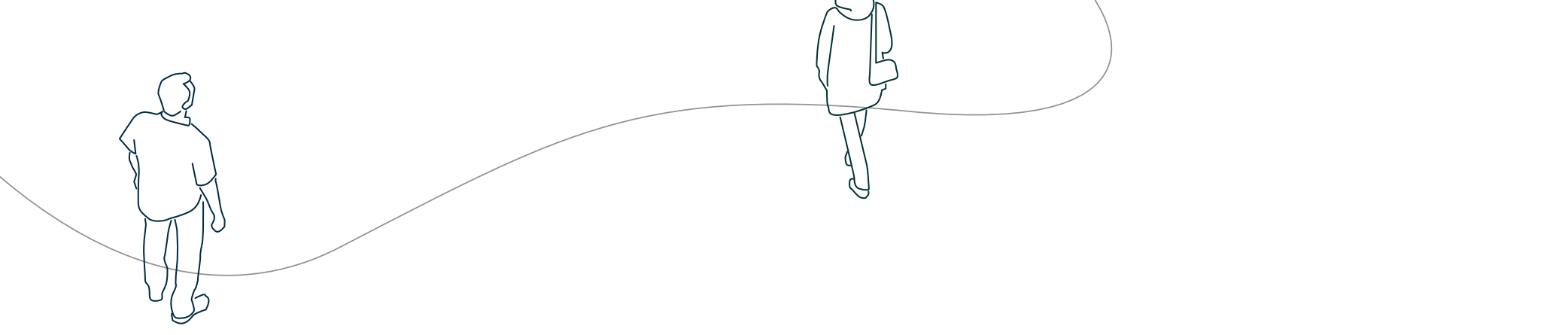




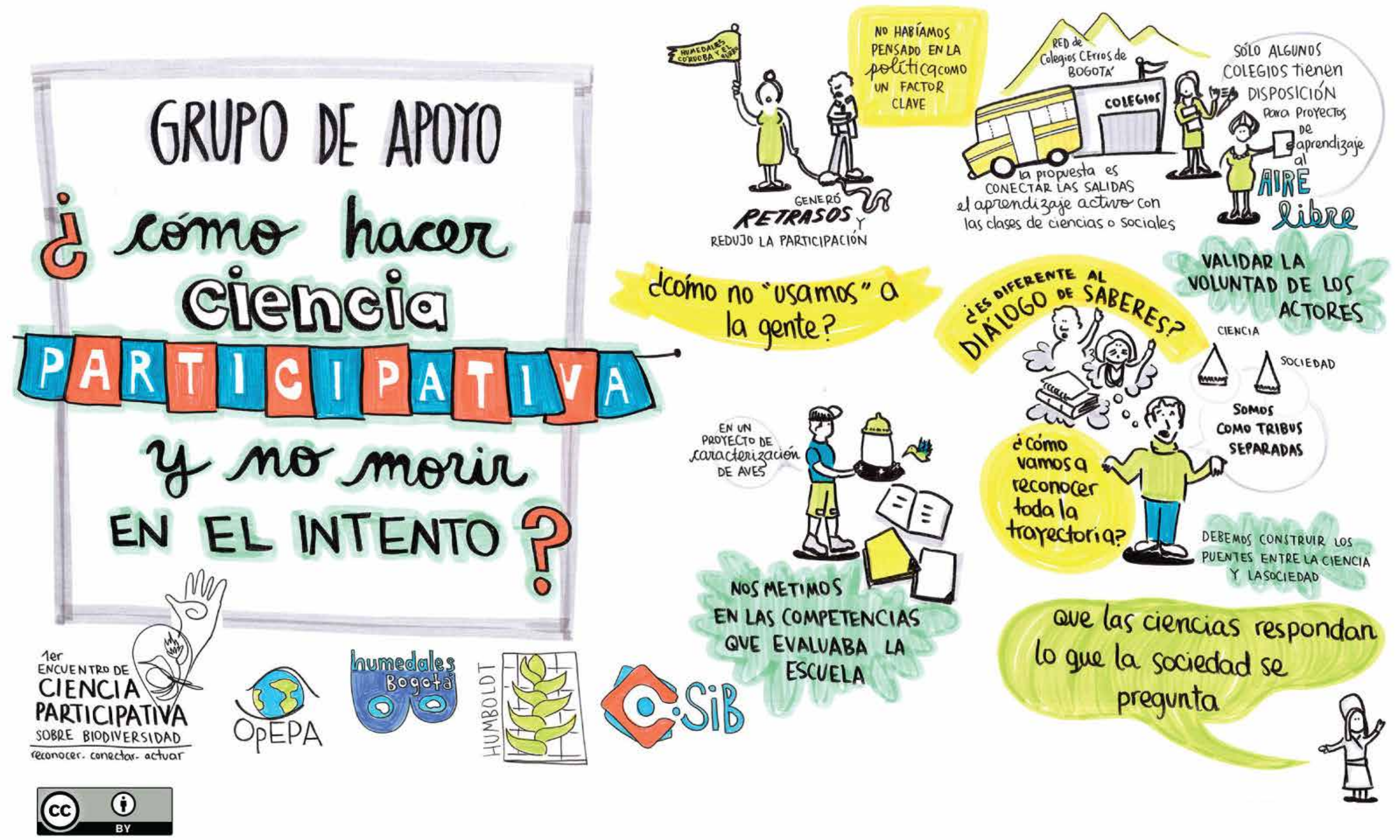



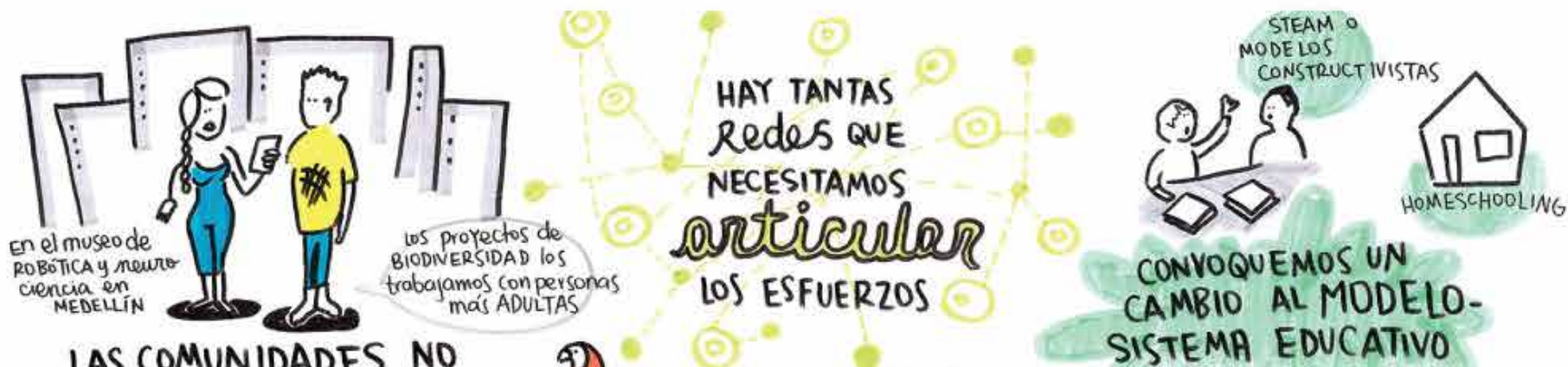

LAS COMUNIDADES NO PRIORIZARON LA

Biodinrersidad

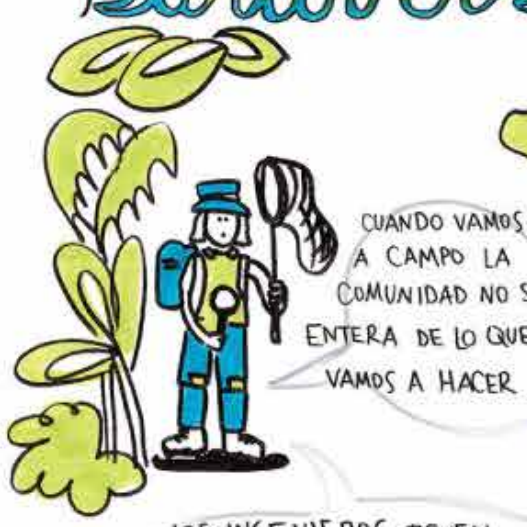

LOS INGENIEROS TENEN

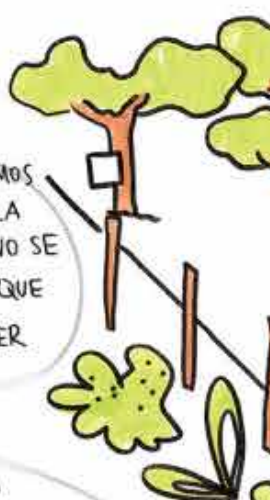

que CoNSULTAR POR los DEPARTAMENTOS

DE Responsabilidad social DE SUS EMPRESAS

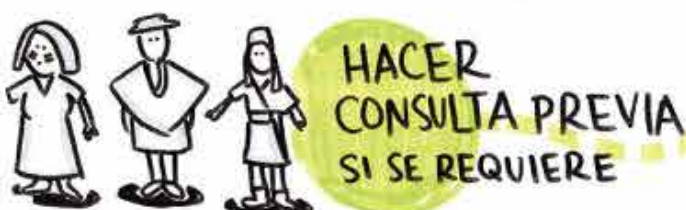

(c) (i) COS

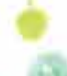
Trabajamos COMO NIÑOS PARA ENTENDER LA COMPLEJIDAD
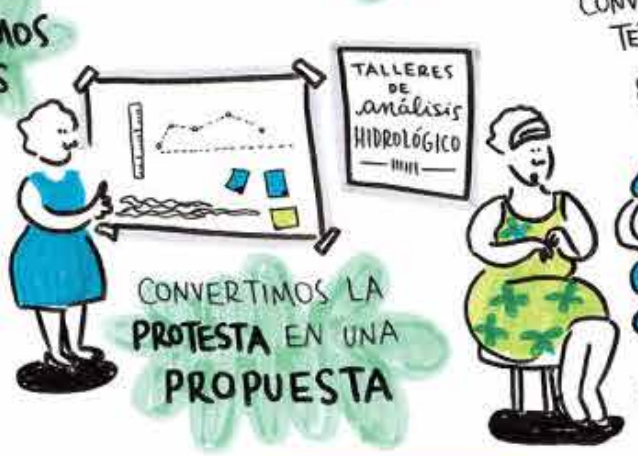

CONGETTMOS EL CONOCIMENT TÉCNICO DE PIANGUAY

MANGLARES

i) ARRULLOS (f) ¿ CÓMo MOTIVAMOS EL ¿ CÓMO GENERAMOS comunitario? CON POCOS 3 tiempo En El TerRtTorio contimuidad? ? 3 tiempo en ELTERritorio comtimuidad? continuidad? प्री

INVOLUCRAR NOENENAS COMUNIDAD गु?
CURRULAOS SER

CULTURALES

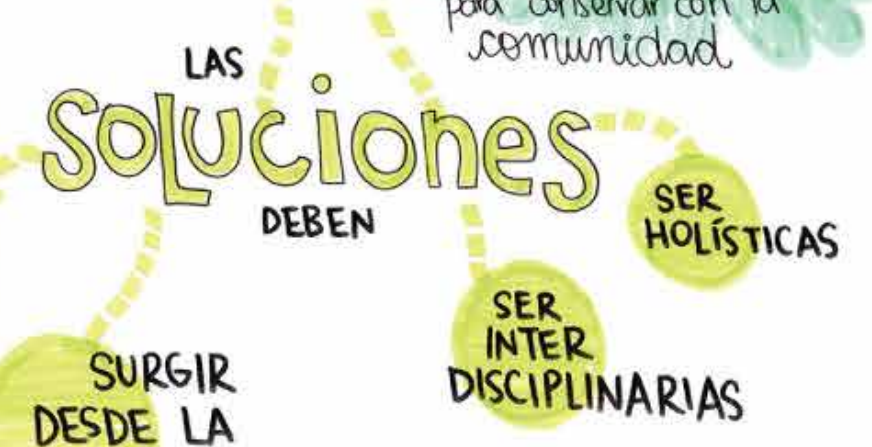

DESDE LA

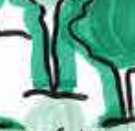

IPLINARIAS
BOSQUE MODELO para conservar con la comunidad CONTEMPLAR DEAMBIENTE

POLITICA \& 3$\} ?$ EN NARIÑ LA PrEGUNTA $\left.\left.\begin{array}{l}\text { ESLQUEE ESTAMOS } \\ \text { HACIENDO }\end{array}\right\}\{\}\right\} \begin{aligned} & \text { NEGOCIOS } \\ & \text { VERDES }\end{aligned}$ HACIENDO CON TODO ESTO?

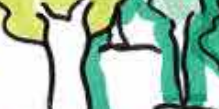

desde 2016 

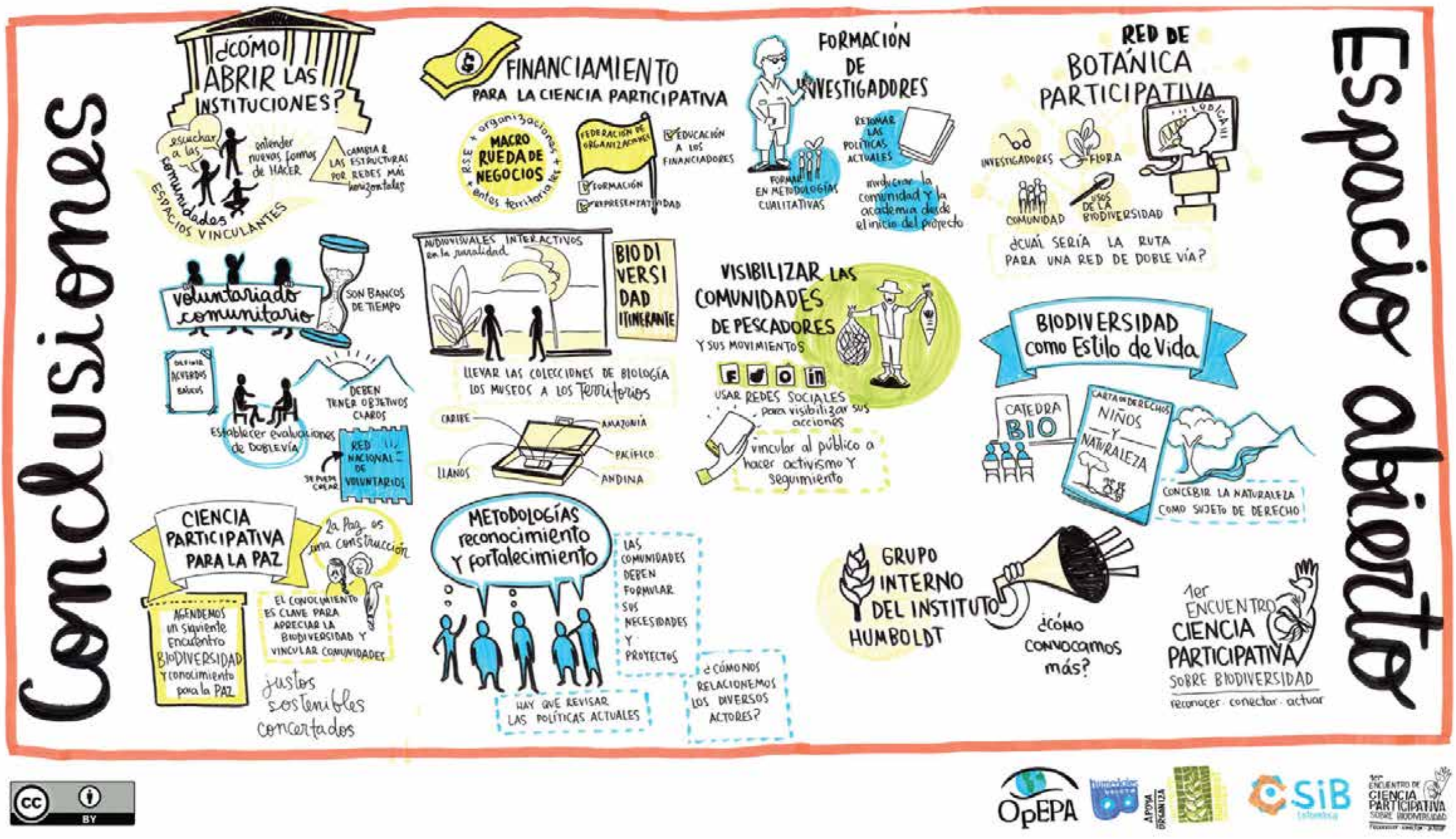
Además de las propuestas concretas, cada grupo compartió el resumen de sus reflexiones:

\section{Ciencia participativa para la paz}

Ante un escenario de construcción de paz como el que atraviesa Colombia después de más de 50 años de una guerra civil, la construcción de conocimiento colectivo sobre la biodiversidad se convierte en un vehículo para el diálogo, para el reconocimiento del territorio a la luz de nuevos retos para la conservación de áreas protegidas y la gestión sostenible de la diversidad biológica del país.

La discusión del tema asociada a la construcción de paz implica el ejercicio de los habitantes y la reconciliación con sus territorios. Se propone el desarrollo de un encuentro de ciencia participativa para la construcción de la paz y la conservación de la biodiversidad. La idea es que se constituya un grupo organizador que permita hacer posible esta iniciativa.

\section{Formación de investigadores y nuevas metodologías}

No es necesario inventar la rueda, es necesario construir sobre lo que ya está. Es importante hacer una mezcla de enfoques entre lo cualitativo y lo cuantitativo. La propuesta es invitar a los proyectos para que generen estrategias de apropiación social del conocimiento en sus iniciativas.

Las comunidades deben formular sus necesidades y proyectos. También es necesario incentivar un mejor relacionamiento de los actores actuales.

\section{Financiamiento para proyectos de ciencia participativa}

Crear una macrorrueda de negocios entre organizaciones y empresas comerciales. Es necesario también que las organizaciones se agremien para generar desde allí posibilidades. Generar una bolsa de valores desde las empresas interesadas en invertir en responsabilidad social y biodiversidad, para que las instituciones conozcan y abran nuevas alternativas de desarrollo de proyectos de ciencia participativa.

\section{Biodiversidad como estilo de vida}

La propuesta está enfocada en que los niños puedan apropiarse de conocimientos asociados a la biodiversidad: la existencia de una cátedra 'BIO' para transformar desde la infancia. Por otra parte, generar una carta de derechos para los niños y la naturaleza, y finalmente una ley de naturaleza para que pueda existir una apropiación del tema.

\section{Mesa de apertura institucional}

Idea 1: Activar tres modos: filiación, gobernanza y propiedad.

Filiación: busca darle continuidad a los procesos que se llevan a cabo entre la institución y la sociedad. Pretende disolver las barreras que existen entre las instituciones y las comunidades. 
Gobernanza: evaluar quién debe tomar las decisiones dentro de la institución y la pertinencia de estas decisiones.

Propiedad: garantizar el acceso de todos los involucrados a la información (especialmente cuando se trata de instituciones públicas donde el dinero para la ejecución proviene de los ciudadanos).

Estos modos deben estar enmarcados en un proceso de escucha en el que se busca transformar el modelo jerárquico en uno redárquico (de redes).

Idea 2: Ciclo de apertura institucional.

Las instituciones deben decidir abrirse de forma autónoma, teniendo una actitud de escucha frente a las necesidades y las problemáticas de la sociedad. Con esto se puede propiciar un diálogo en el que se generen políticas institucionales transparentes que sean capaces de satisfacer los requerimientos de los participantes.

Es importante que en este ciclo se tenga conciencia de las implicaciones de un proceso de transición y retroalimentación.

\section{Voluntariado comunitario}

Aunque hubo discusión sobre el concepto ( el cual varía), el consenso evidencia que en Colombia no es evidente la cultura del voluntariado. Se propone realizar una Red Nacional de Voluntariado, y además motivar o invitar a que otras organizaciones implementen procesos o semillas de voluntariado como una oportunidad de fortalecer el trabajo participativo con la sociedad civil (en múltiples frentes: local, presencial, virtual, etc.).

\section{Red Botánica Participativa}

¿Cómo acercar a la gente a las plantas? ¿cómo combatir la miopía verde?: la propuesta es generar una convocatoria inicial para generar una red educativa, comunicativa para expertos y no expertos y generar materiales didácticos para fortalecer la conciencia frente a la existencia de las plantas.

\section{Biodiversidad itinerante}

Consolidar una red de museos de ciencias y establecer una estrategia que permita que la biodiversidad y el conocimiento asociado pueda ser itinerante y llegar a diversos públicos. Museos al alcance de todos para poder alcanzar a diferentes públicos, esto a través de la Red de museos de ciencias e historia natural.

\section{Estrategias para visibilizar al pescador}

Un movimiento de pescadores del Magdalena Medio puede posicionarse a través de iniciativas o medios que trabajen y aborden el tema. En particular utilizando las redes sociales para visibilizar sus acciones, promover el activismo y el seguimiento.

\section{Coherencia institucional para la gestión social del conocimiento}

Consolidar un grupo de trabajo al interior del Instituto Humboldt para hacer una conceptualización sólida que permita el trabajo y el liderazgo frente a otras organizaciones. Convocar la realización de una investigación orientada a la coyuntura de paz y posconflicto. 


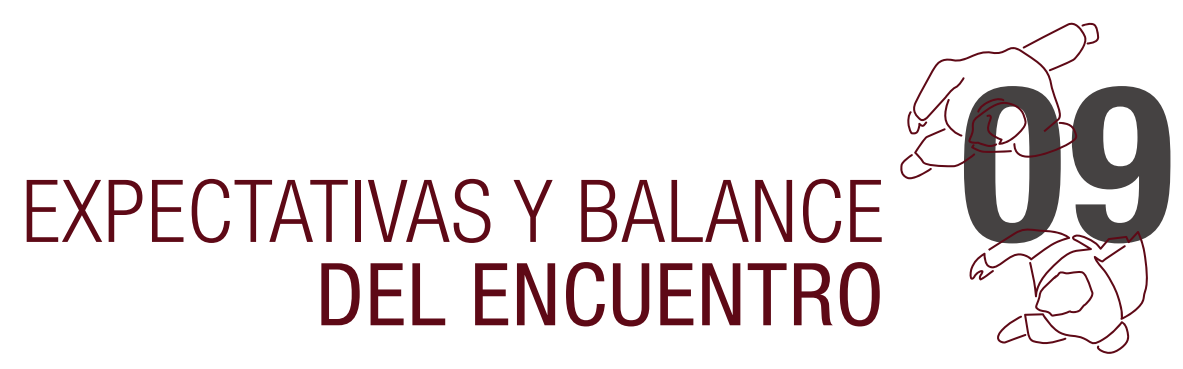

Intercambiar experiencias entre los practicantes e interesados en ciencia participativa fue una de las principales expectativas y a la vez resultados del Encuentro. Contar con espacios de diálogo y de construcción colaborativa de propuestas también fue ampliamente valorado; sin embargo, el tiempo fue corto y los participantes sintieron la falta de escenarios para conocerse entre todos y compartir de una forma más amplia sus avances y expectativas.

La oportunidad de conocerse y conectarse fue otro de los aspectos positivos. Especialmente por la creación de un grupo en una red social que se espera contribuya a tejer canales de comunicación. En este primer encuentro participaron principalmente personas con estudios en ciencias ambientales y experiencia en proyectos de ciencia participativa, vinculadas a organizaciones no gubernamentales. Es necesario trabajar en una participación multisectorial, interdisciplinaria y pluricultural más amplia para futuros espacios, incluyendo a las comunidades.

Cabe resaltar que aunque hubo una amplia participación desde las ciencias ambientales, fue evidente y enriquecedora la divergencia de opiniones y visiones sobre la ciencia participativa. Especialmente desde las aproximaciones de las ciencias sociales y las experiencias con comunidades indígenas, campesinas y rurales en las que el diálogo de saberes ha demostrado que la construcción de conocimiento debe ser un proceso colaborativo entre pares.

El interés en aprender o fortalecer las bases conceptuales en ciencia participativa se abordó para algunos aspectos base a través de los conferencistas. Para futuros espacios se identificaron temas de interés a trabajar como monitoreo participativo, comunicación y educación, metodologías para el desarrollo de proyectos de ciencia participativa y tecnología, datos e información.

El balance del Encuentro fue positivo, los asistentes participaron activamente y encontraron oportunidades de colaboración. Se reconocieron como una fuerza común que busca trabajar en la generación de conocimiento de la mano con la comunidad que permita incidir en la gestión sostenible de la biodiversidad. Para la gran mayoría era una sorpresa ver 27 organizaciones trabajando en este tema y más aún con proyectos a nivel nacional, en los que compartían necesidades y expectativas. Manifestaron su amplio interés en seguir trabajando y sumar esfuerzos.

El Encuentro fue la ventana para conectar una comunidad de practicantes e interesados que ven en la ciencia participativa un camino para construir un conocimiento oportuno, desarrollado desde lo local a partir del diálogo de saberes y que se conecta efectivamente con la toma de decisiones. 
¿El encuentro fue útil?

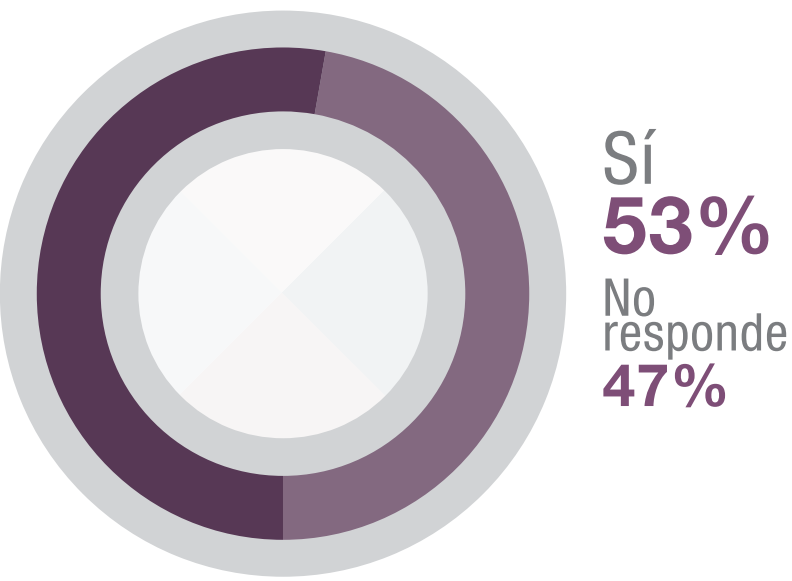

¿Cómo lo califica?

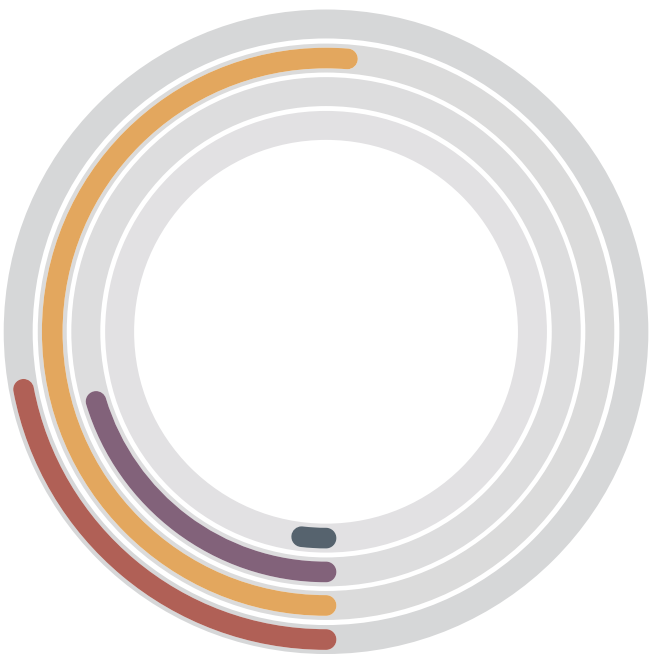

(2) 3 (4) 5

5 Excepcional, de manera significativa y consistente excedió positivamente las expectativas.

4 Altamente efectivo, cumplió y en ocasiones excedió positivamente las expectativas.

3 Efectivo, cumplió con su propósito.

$\underline{2}$ Inconsistente, estuvo lejos de las expectativas.

1 Insatisfactorio, no cumplió con las expectativas. 


\section{¿Cuáles eran las expectativas del Encuentro?}

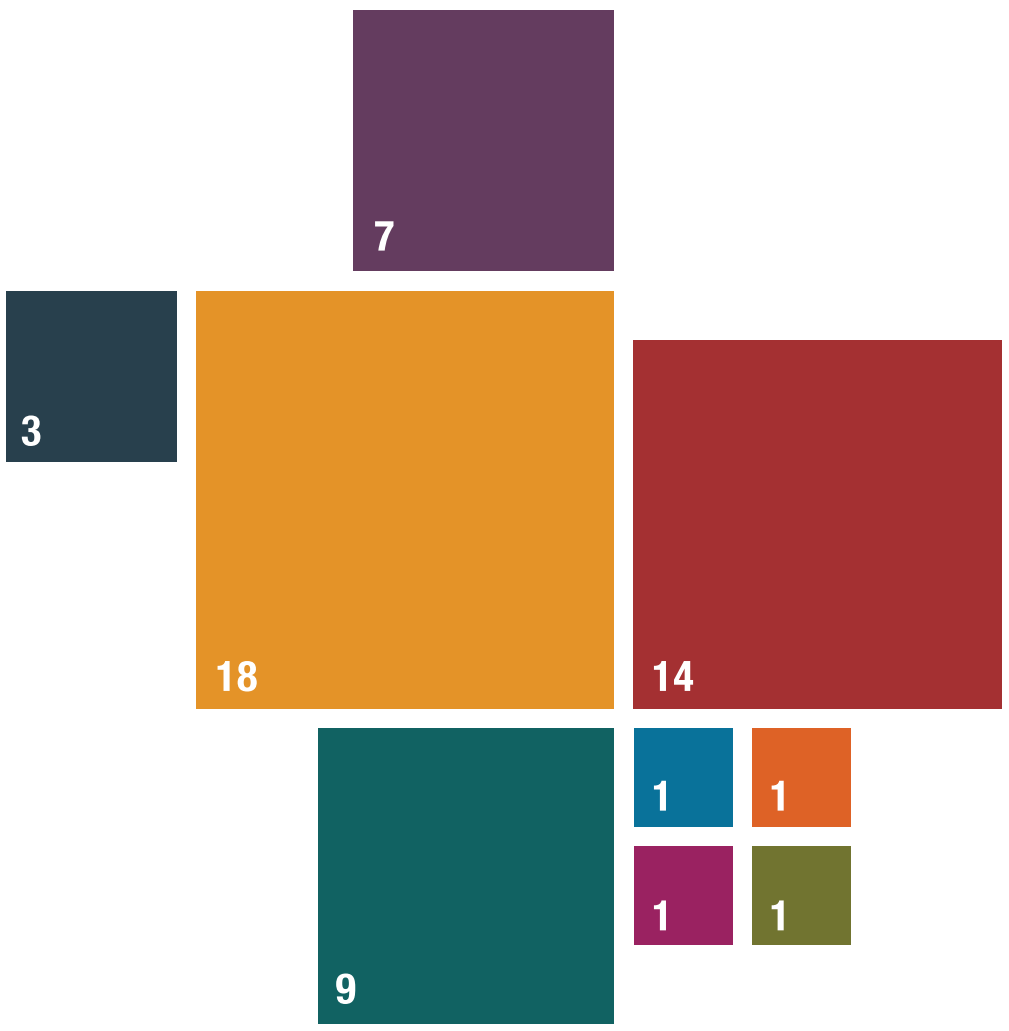

18 Intercambiar experiencias en proyectos de ciencia participativa.

14 Aprender y fortalecer bases conceptuales y metodológicas.

9 Hacer contactos y redes de trabajo.

7 Conocer iniciativas de ciencia participativa para integrar y articular.

3 Conocer tecnologías y herramientas.

1 Ver el panorama nacional e internacional de la ciencia participativa.

1 I Ientificar formas para ampliar la divulgación e impacto de los procesos de ciencia participativa.

1 Identificar mecanismos para medir impactos de la ciencia participativa.

1 Proponer proyectos de inventario y/o monitoreo científico. 
¿Cuáles fueron los aspectos positivos del Encuentro?

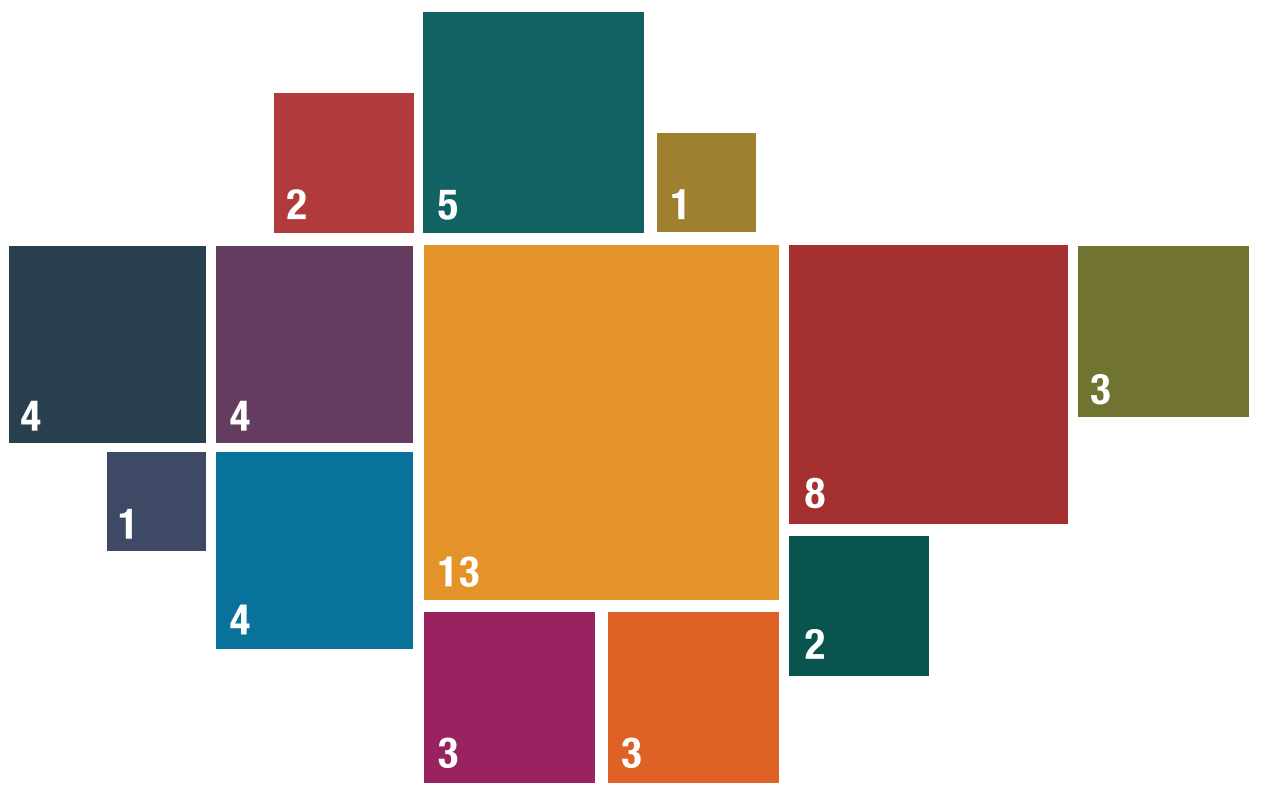

13 Compartir experiencias, perspectivas y expectativas.

8 Metodología participativa.

5 Creación de un espacio para seguir conectados.

4 Participantes.

4 Conexiones realizadas.

4 Divergencia de visiones y opiniones.

3 Participación activa de los asistentes y trabajo colaborativo.

3 Conferencias.

3 Logística.

2 Propuestas grupales.

2 Conocimiento adquirido (Aprendizaje).

1 Diversidad institucional.

1 Infografías en vivo. 


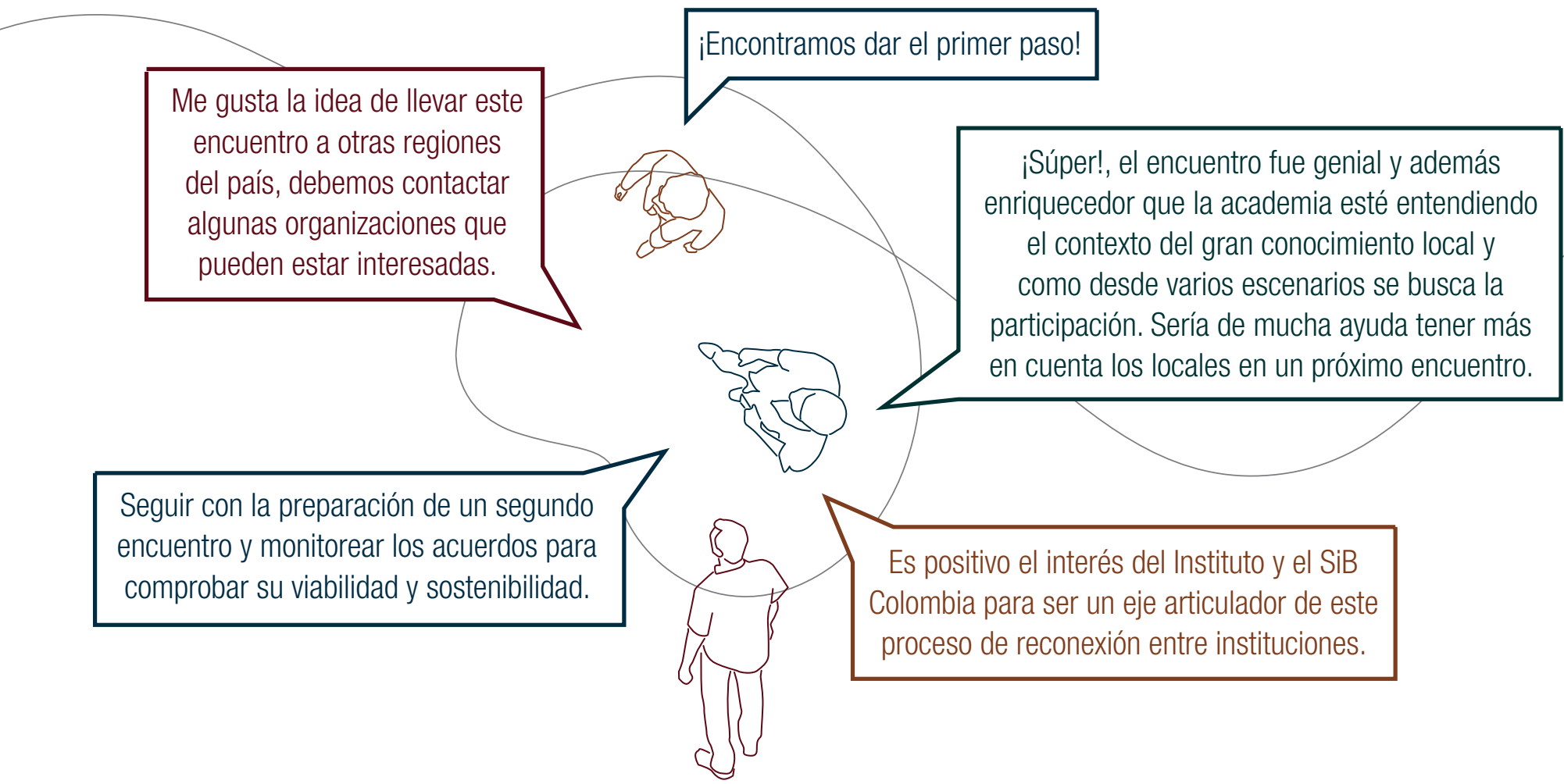

\section{¿Qué temas consideraba prioritario abordar en el Encuentro?}

\section{Comunidad de práctica o red de colaboración}

\section{Comunicación y Educación}
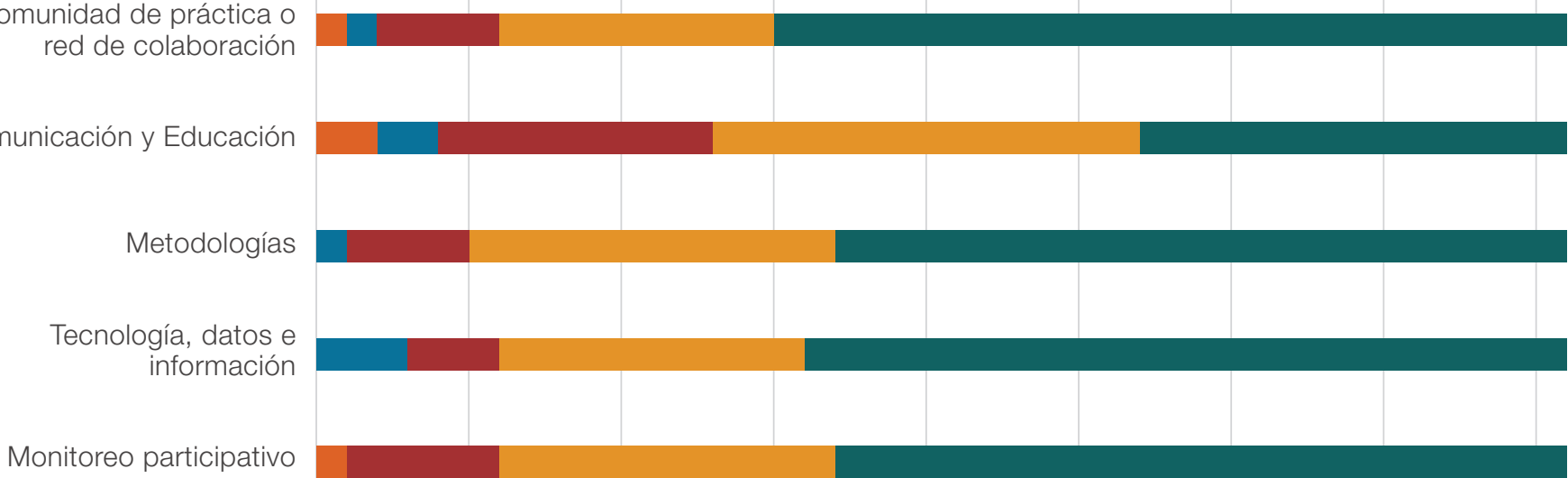

Monitoreo participativo 


\section{¿Cómo estuvo la organización?}

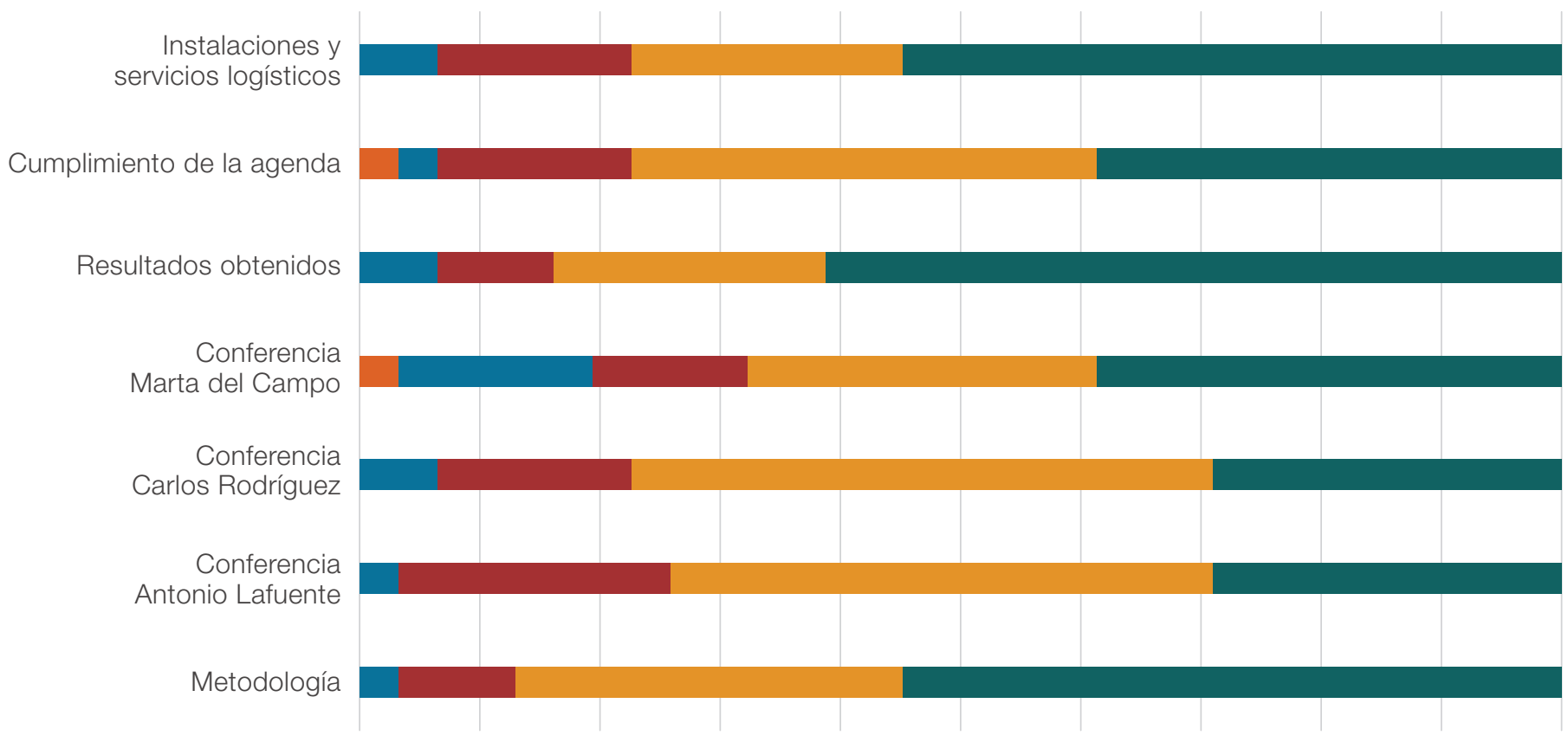

$12 \mathbf{3} 345$

\section{¿Qué se debería mejorar para un futuro Encuentro?}

- Mayor diversidad de invitados: organizaciones y comunidad. Presencia intersectorial.

- Mejorar metodología: dinámica para conocer a todos los participantes, agenda previa y tiempos para interacción.

- Cumplimiento de la agenda.

- Mayor tiempo para poder abordar todos los temas.

- Concreción.

- Participación de otras disciplinas: por ejemplo sociales y económicas.

- Conexión con el desarrollo de otras políticas e iniciativas afines.

- Generar el directorio de contactos en el Encuentro y disponerlo antes del cierre.

- Tres charlas en un día puede resultar agotador.

- Formalizar resultados y acuerdos. 


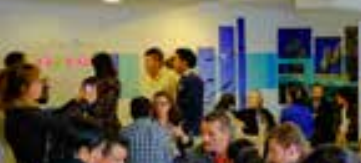
6inc 2
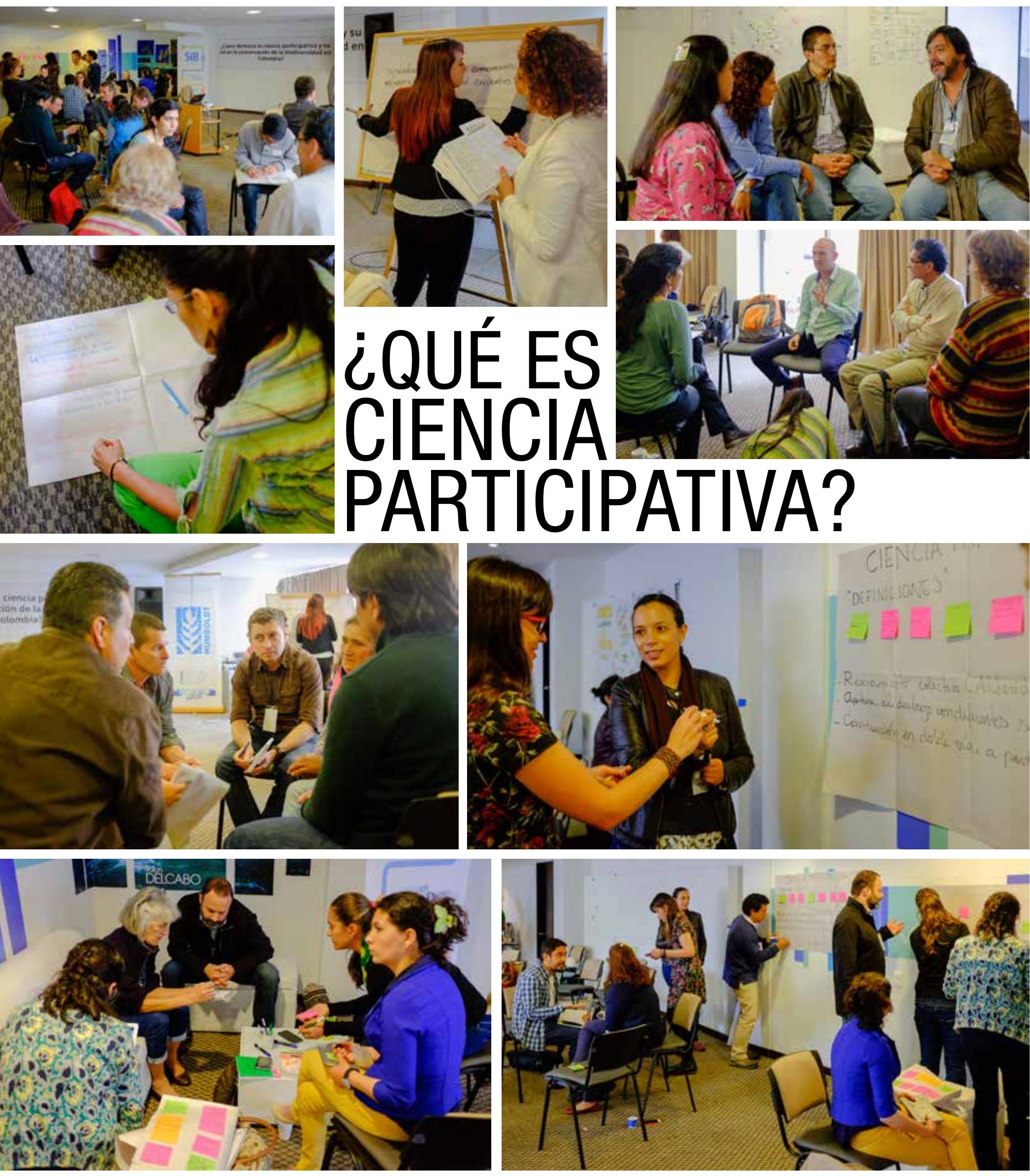

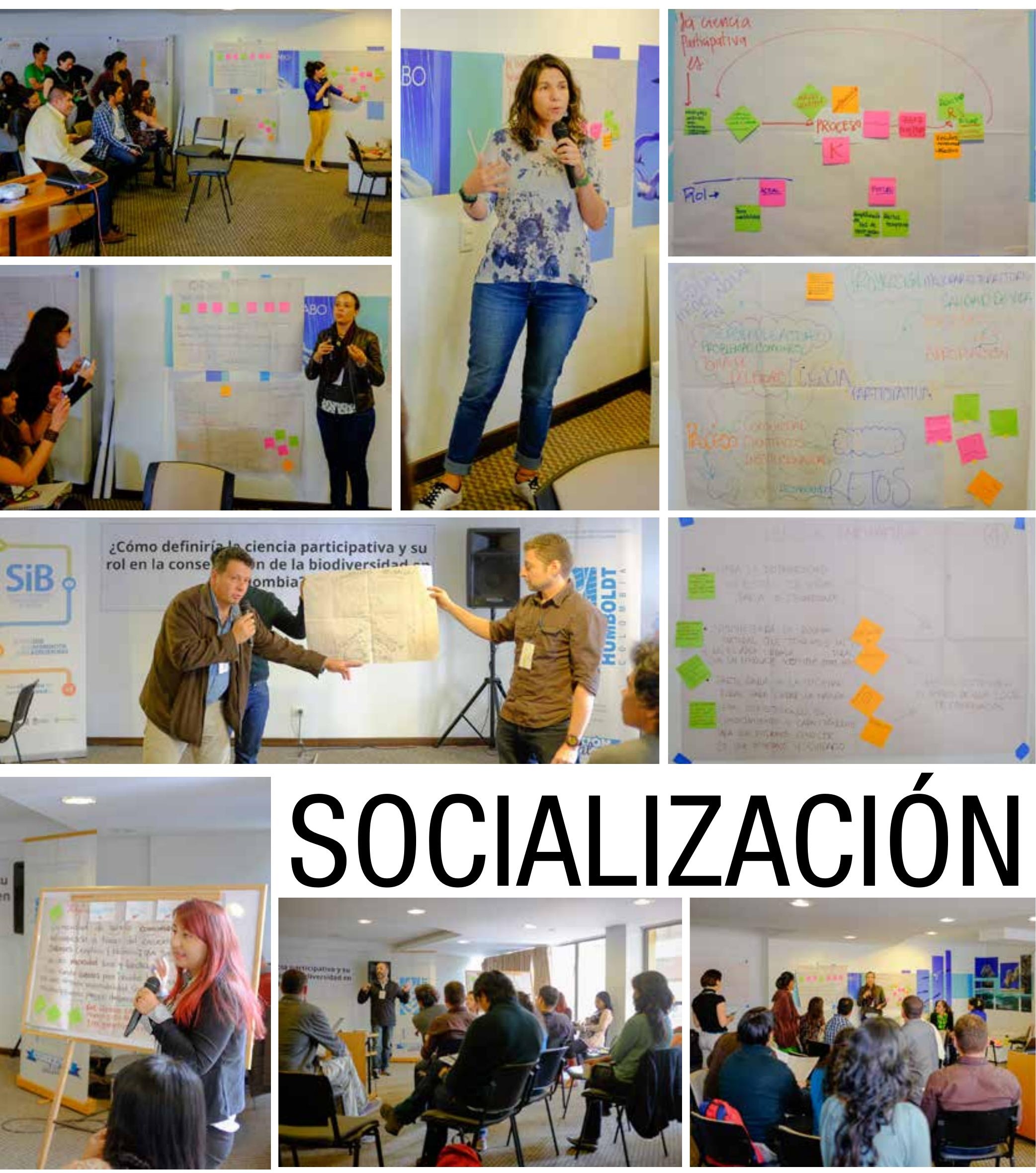

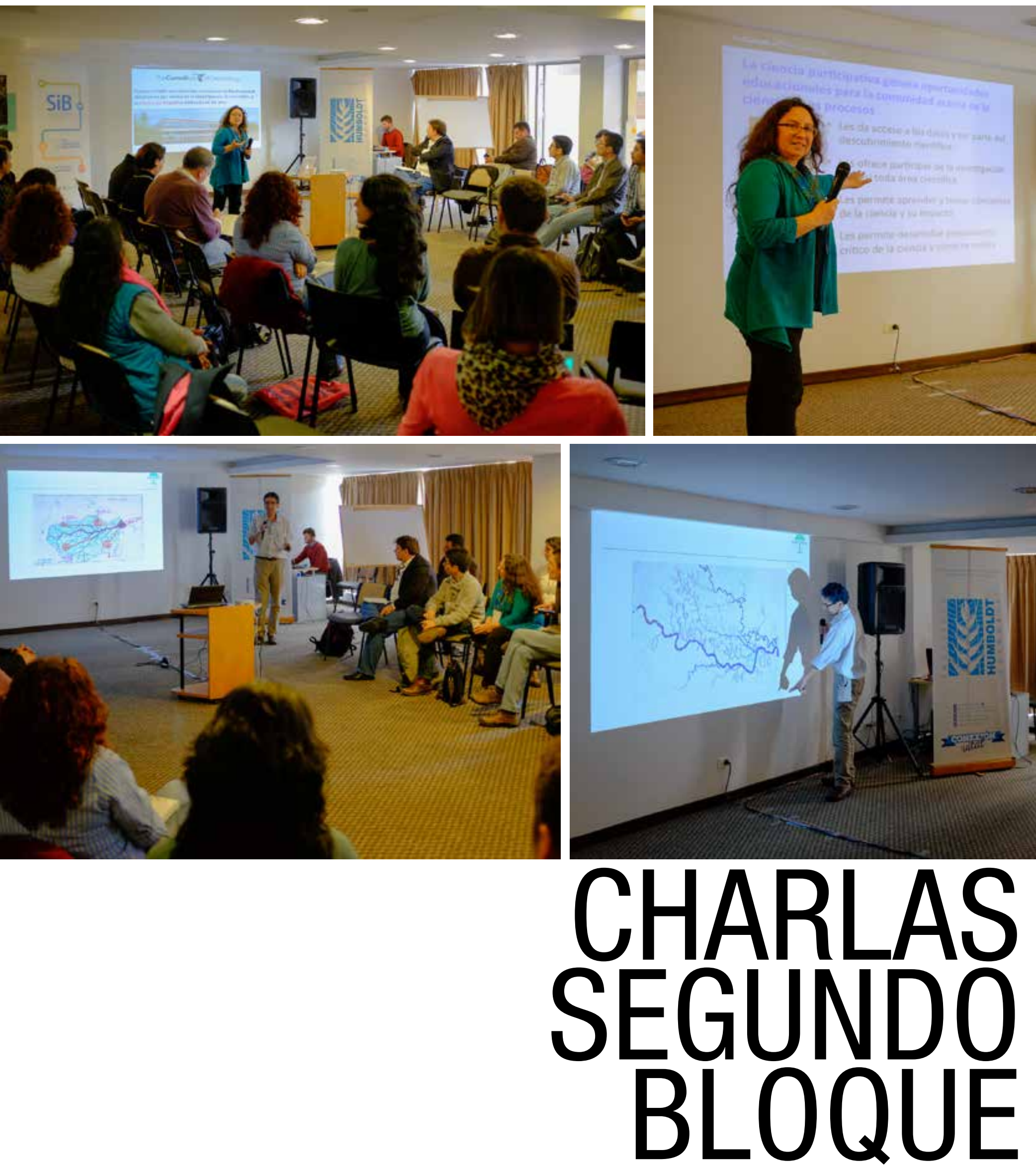

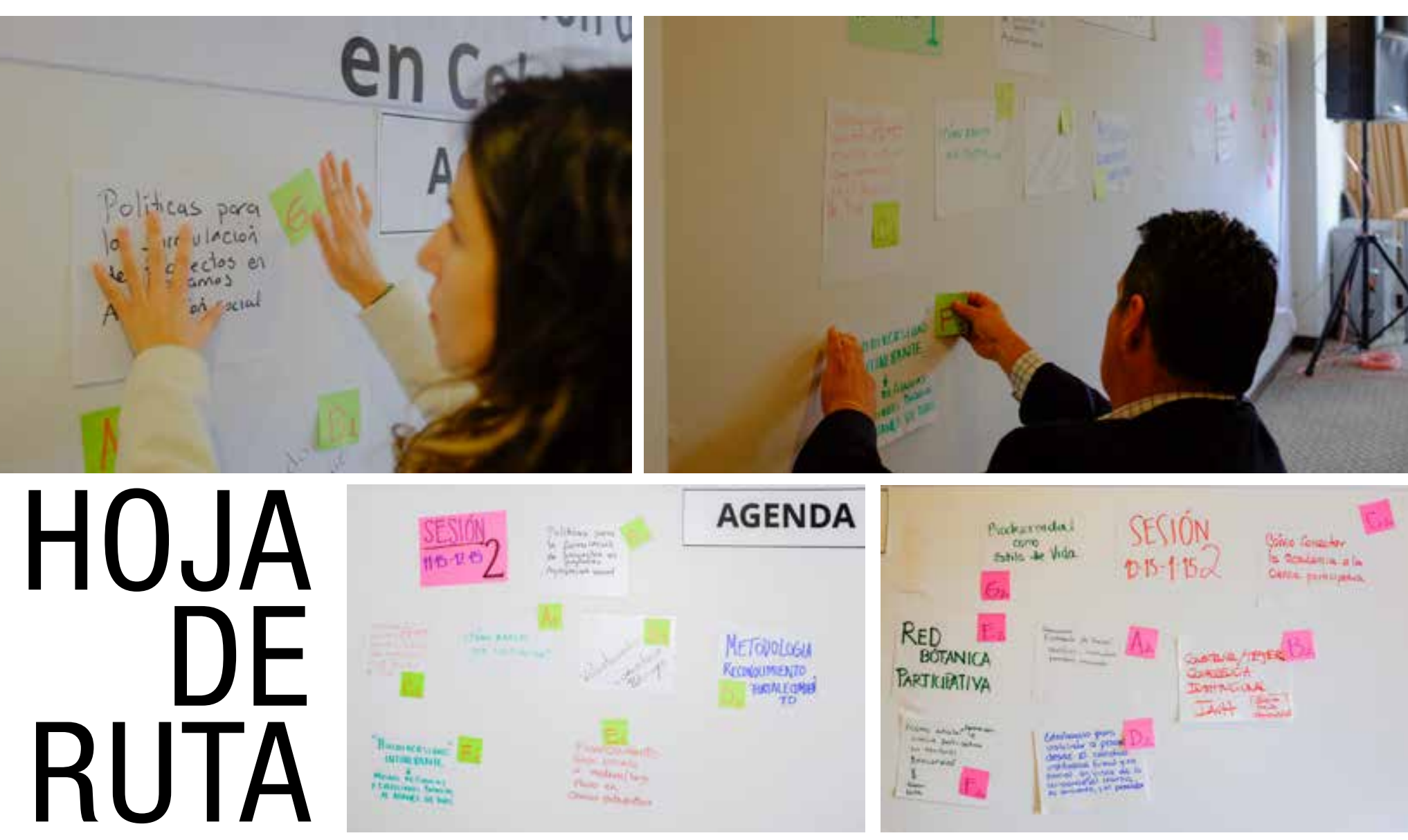

¿Cómo lograr una ciencia participativa que incida en la conservación de la biodiversidad en Colombia?
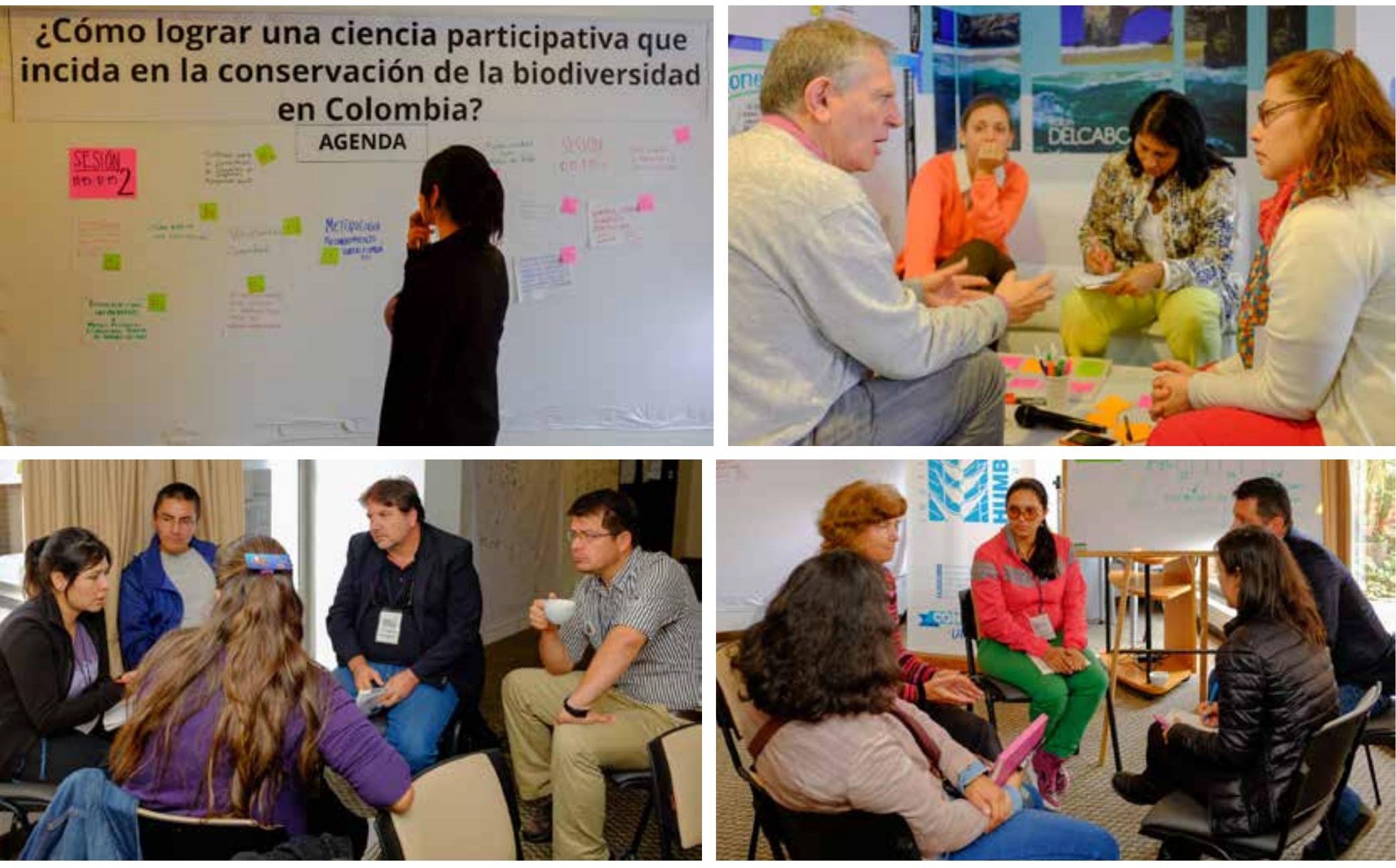

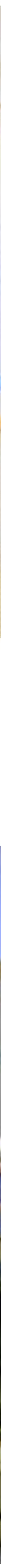


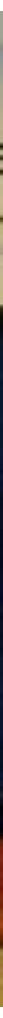

DIANA RENGIFO

Oficina Comunicaciones

Instituto Humboldt

FELIPE VILLEGAS

Oficina Comunicaciones

Instituto Humboldt

\section{JEIMMY DIAZ}

Programa de Evaluación y Monitoreo de la Biodiversidad Instituto Humboldt

JORGE ESCOBAR

Fundación Humedales Bogotá

KAREN SOACHA

Sistema de Información sobre

Biodiversidad de Colombia

(SiB Colombia)

\section{LAURA CABRERA}

Sistema de Información sobre Biodiversidad de Colombia

(SiB Colombia)

LUIS CAMARGO

Fundación Opepa
LUZ HELENA OVIEDO

Oficina Comunicaciones

Instituto Humboldt

NATALIA GÓMEZ

Sistema de Información sobre

Biodiversidad de Colombia

(SiB Colombia)

VALERIE DEAN

Sistema de Información sobre

Biodiversidad de Colombia

(SiB Colombia)

XIMENA BORRÉ

Oficina Comunicaciones

Instituto Humboldt

\section{SANDRA PEÑA}

Programa de Evaluación y Monitoreo de la Biodiversidad Instituto Humboldt

\section{EQUIPO LOGÍSTICO}

Hotel Viaggio Urbano

\author{
JULIANA SERRANO
}

Amazink Studio S.A.S 


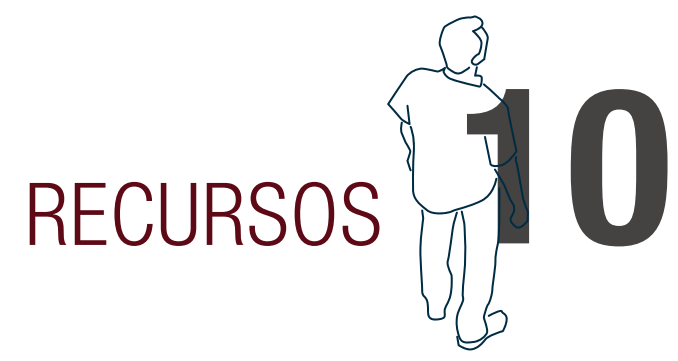

El Encuentro se caracterizó por ser un espacio de construcción colaborativa, en el que los insumos y resultados alcanzados están disponibles para uso y difusión de la comunidad. En este sentido, la documentación generada (imagen del evento, afiche de invitación, videos de las charlas, fotos e infografías) es de carácter abierto, está disponible en el sitio webdel Instituto Humboldt, Sección 'Ciencia Participativa' y se comparte utilizando las licencias Creative Commons indicadas para cada producto.

Entre los recursos generados con el Encuentro están los espacios de conversación en Facebook y el grupo que se encargará de movilizar los compromisos.

\section{Grupo en Facebook \#Ciencia Participativa Col}

Para mantener y expandir las conexiones entre los participantes en el Encuentro se creó un espacio virtual en Facebook. El grupo \#CienciaParticipativa Col es abierto y espera continuar con su crecimiento para integrar a líderes de iniciativas, apasionados, participantes, movilizadores y en general a la comunidad interesada en expandir la ciencia participativa.

\section{Grupo de movilización de compromisos}

Equipo: Juliana Cepeda, Mildrey Mendoza, Juan Restrepo y Karen Soacha.

Serán los encargados de invitar y seguir movilizando los compromisos y propuestas del Encuentro. 


\section{$\$$ Naturalista}

\section{COLOMBIA}

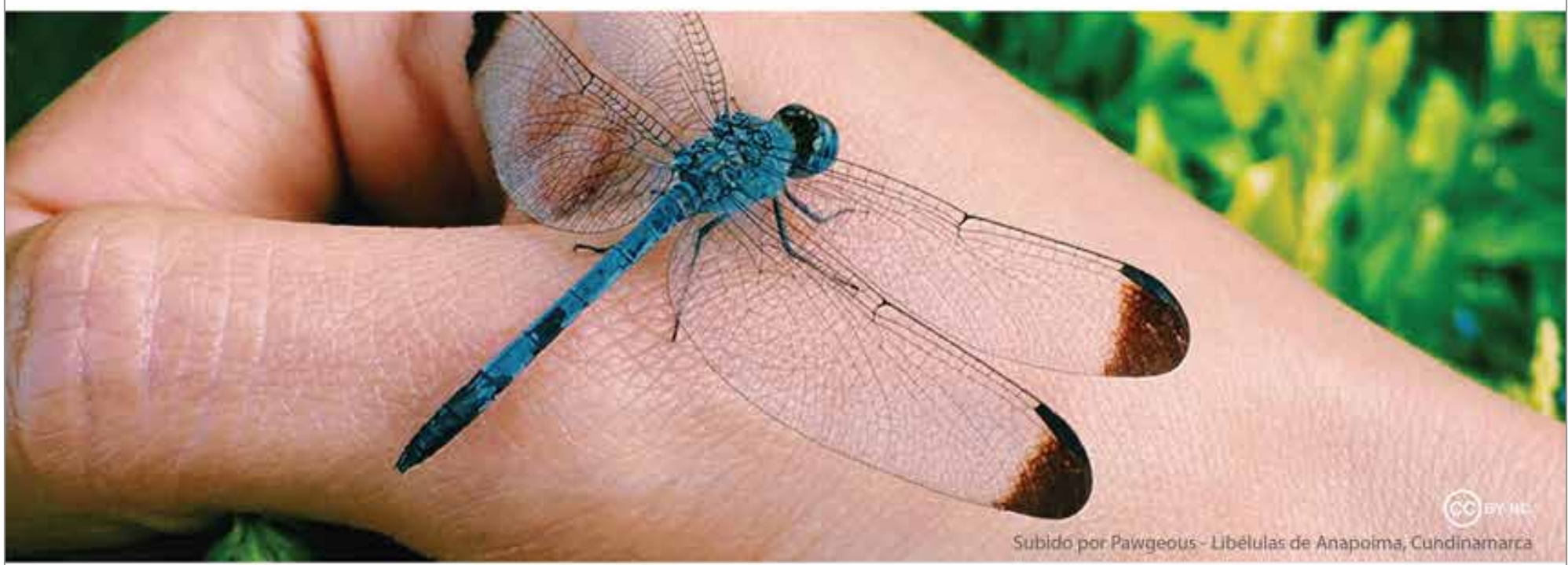

\section{Cómo funciona}

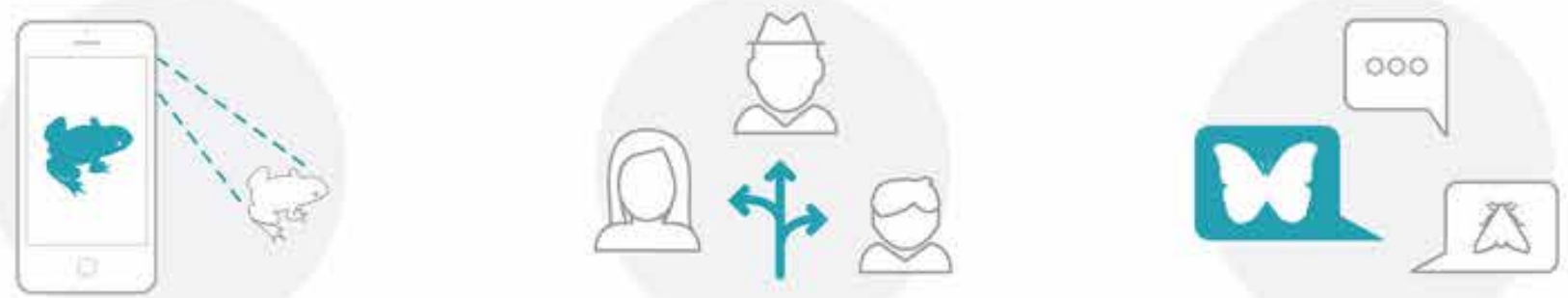

(1)

(2)

(3)

\section{Comparte tu pasión por la naturaleza}

\section{WEB : naturalista.biodiversidad.co}

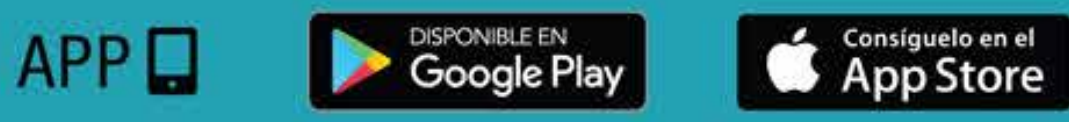

Descarga iNaturalist y configura Colombia como pais para utilizar Naturalista 

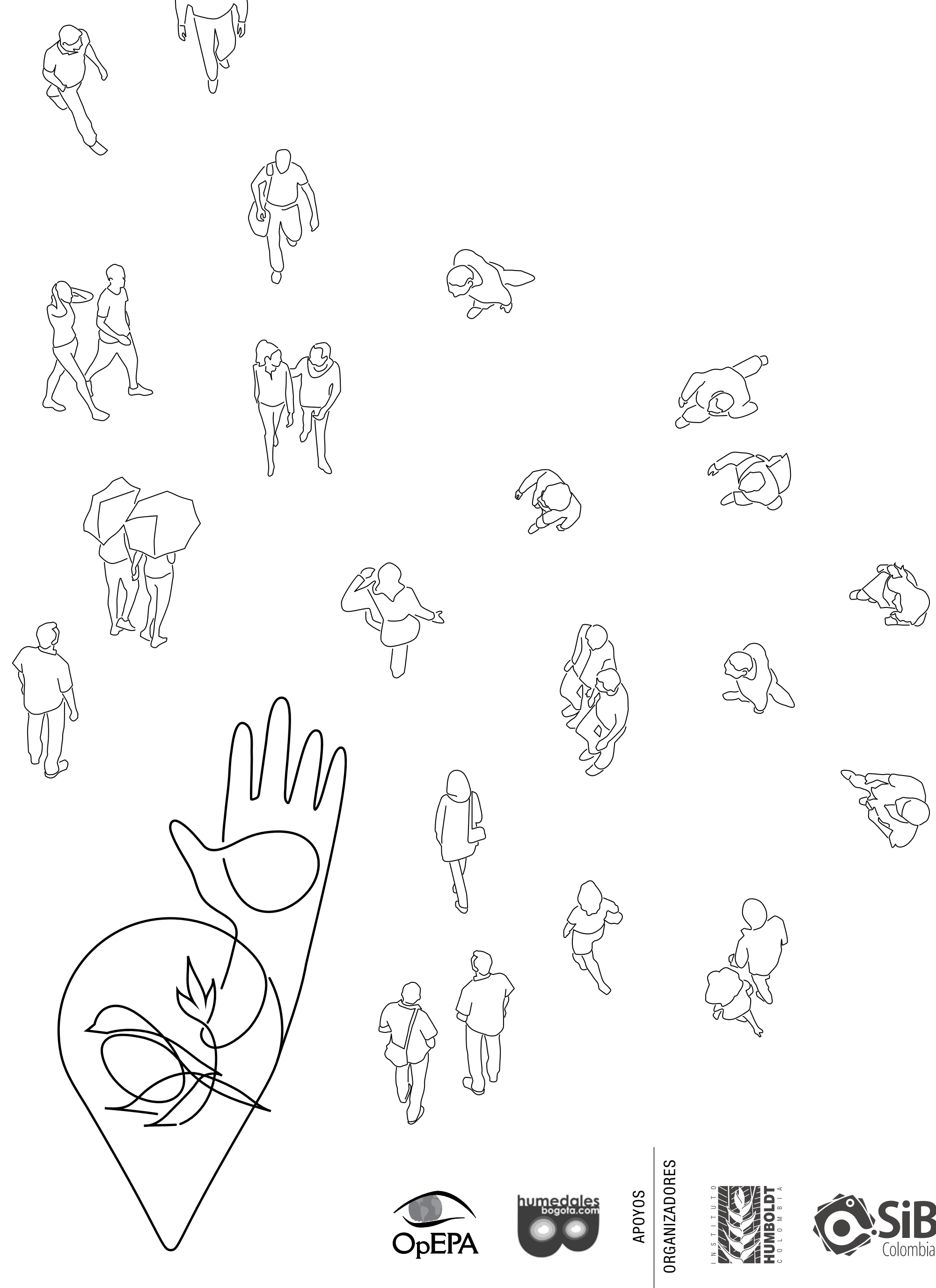